\title{
Diversity of two forms of DNA methylation in the brain
}

\author{
1 Department of Anatomy and Cell Biology, Indiana University School of Medicine, Indianapolis, IN, USA \\ ${ }^{2}$ Agricultural and Biological Engineering, Bindley Bioscience Center, Purdue University, West Lafayette, IN, USA \\ ${ }^{3}$ Division of Nephology, Department of Medicine, Indiana University School of Medicine, Indianapolis, IN, USA \\ ${ }^{4}$ Stark Neuroscience Research Institute, Indiana University School of Medicine, Indianapolis, IN, USA
}

Yuanyuan Chen ${ }^{1}$, Nur P. Damayanti ${ }^{2}$, Joseph Irudayaraj ${ }^{2}$, Kenneth Dunn ${ }^{3}$ and Feng C. Zhou ${ }^{1,4 *}$

Edited by:

Douglas M. Ruden, Wayne State

University, USA

\section{Reviewed by:}

Vincent E. Sollars, Marshall

University, USA

Eugenia XU, Raymond and Beverly

Sackler Foundation, USA

Yuhong Fan, Georgia Institute of

Technology, USA

*Correspondence:

Feng C. Zhou, Department of Anatomy and Cell Biology, and Stark Neuroscience Research Institute, MS508, Indiana University School of Medicine, Indianapolis, IN 46202, USA

e-mail: imce100@iu.edu
DNA methylation 5-methylcytosine $(5 \mathrm{mC})$ predicts a compacting chromatin inaccessible to transcription. The discovery of 5-hydroxymethylcytosine $(5 \mathrm{hmC})$, which is derived from $5 \mathrm{mC}$, adds a new dimension to the mechanism and role of DNA methylation in epigenetics. Genomic evidence indicates that the $5 \mathrm{hmC}$ is located in the alternate regions to $5 \mathrm{mC}$. However, the nature of $5 \mathrm{hmC}$, as compared with classical $5 \mathrm{mC}$ remains unclear. Observing the mouse brain through embryonic development to the adult, first, we found that $5 \mathrm{hmC}$ is not merely an intermediate metabolite of demethylation, but is long lasting, chromatically distinct, and dynamically changing during neurodevelopment. Second, we found that $5 \mathrm{hmC}$ distinctly differs from $5 \mathrm{mC}$ in its chromatin affiliation during neural stem cell (NSC) development. Thirdly, we found both $5 \mathrm{mC}$ and $5 \mathrm{hmC}$ to be uniquely polarized and dynamic through the NSC development. $5 \mathrm{mC}$ was found to progressively polarize with MBD1 and MeCP2, and recruits $\mathrm{H} 3 \mathrm{~K} 9 \mathrm{me} 3$ and $\mathrm{H} 3 \mathrm{~K} 27 \mathrm{me} 3$; while $5 \mathrm{hmC}$ progressively co-localizes with MBD3 and recruits $\mathrm{H} 3 \mathrm{~K} 4 \mathrm{me} 2$. Critical differential binding of $5 \mathrm{mC}$ with MBD1, and 5hmC with MBD3 was validated by Resonance Energy Transfer technique FLIM-FRET. This transition and polarization coincides with neuroprogenitor differentiation. Finally, at the time of synaptogenesis, $5 \mathrm{mC}$ gradually accumulates in the heterochromatin while $5 \mathrm{hmC}$ accumulates in the euchromatin, which is consistent with the co-localization of $5 \mathrm{hmC}$ with Po/ll, which mediates RNA transcription. Our data indicate that $5 \mathrm{mC}$ and $5 \mathrm{hmC}$ are diverse in their functional interactions with chromatin. This diversity is likely to contribute to the versatile epigenetic control of transcription mediating brain development and functional maintenance of adult brain.

Keywords: epigenetics, 5-methylcytosine, 5-hydroxymethylcytosine, chromatin remodeling, histone code, confocal microscopy, FLIM-FRET

\section{INTRODUCTION}

Since its discovery as the second form of DNA methylation in vertebrate tissue, 5-hydroxymethylcytosine $(5 \mathrm{hmC})$, which is most abundant in the brain (Globisch et al., 2010), has been in the eye of the epigenetic storm (Kriaucionis and Heintz, 2009; Tahiliani et al., 2009; Guo et al., 2011; Ito et al., 2011). The discovery of $5 \mathrm{hmC}$ opens a new route for established DNA methylation to regulate gene expression. $5 \mathrm{hmC}$, the oxidized form of $5 \mathrm{mC}$ by the ten-eleven translocation 1,2 , or 3 (TET1,2,3), can be demethylated, also by TET1,2,3, into 5 -formylcytosine ( $5 \mathrm{fC}$ ) and further into 5-carboxylcytosine (5caC) (Wolffe et al., 1999; Wu and Zhang, 2010; Bhutani et al., 2011). The TET enzyme and the generation of $5 \mathrm{hmC}$ have been found to be involved in programming and maintenance of the pluripotency of embryonic stem (ES) cells (Ito et al., 2010) and totipotency of zygotes (Wossidlo et al., 2011). Current research on $5 \mathrm{hmC}$ has primarily focused on its biochemical characterization in vitro and, primarily on its involvement in stem cells and germ lines. Roles of $5 \mathrm{hmC}$ beyond totipotent cells have been highly anticipated. We first showed that $5 \mathrm{mC}$ and $5 \mathrm{hmC}$ form a collaborative program leading the neuronal differentiation during neural tube development (Zhou et al., 2011; Zhou, 2012), that prevention of the program retards the differentiation, and the program also occurs in developing as well as adult neuronogenesis in the hippocampus (Chen et al., 2013). Recent finding on genomic reorganization of DNA methylation point to a potential role in synaptogenesis (Lister et al., 2013). To date, the individual function of the $5 \mathrm{mC}$ and $5 \mathrm{hmC}$ is not clear and is paramount to the understanding of transcription in general, and brain development and function in many ways. While 5mC's association with suppression of transcription is well accepted, the role of $5 \mathrm{hmC}$ is unclear (Bhutani et al., 2011). Recent genomic distribution analyses showed that $5 \mathrm{hmC}$ and $5 \mathrm{mC}$ are distributed in proximity to different categories of histone codes in the embryonic stem (ES) cells (Pastor et al., 2011; Stroud et al., 2011; Williams et al., 2011; Xu et al., 2011), which implicates the potential deviation of their action in ES cells.

Here, we attempt to elucidate the epigenetic role of $5 \mathrm{hmC}$ during brain development throughout adult brain. First, we examined $5 \mathrm{hmC}$ along with $5 \mathrm{mC}$ from early gestation (E8) and throughout the life span of the brain of mice. Second, DNA methylation binding domain (MBD) proteins such as MBD1 and 3 were studied here in conjunction with $5 \mathrm{mC}$ and $5 \mathrm{hmC}$. Third, we characterized the relationship with histone codes and chromatin. Since DNA methylation is tissue specific, the dynamic 
changes between $5 \mathrm{hmC}$ and $5 \mathrm{mC}$ and their associated chromatin markers including select histone codes and MBDs, were evaluated immunocytochemically. Since the physical proximity of the methylcytosine to MBD is difficult to ascertain by immunocytochemistry, the differential binding of $5 \mathrm{mC} / 5 \mathrm{hmC}$ to their MBD partner is further confirmed with high-fidelity Fluorescence Lifetime Imaging based Forster Resonance Energy Transfer (FLIM-FRET).

We report here how $5 \mathrm{mC}$ and $5 \mathrm{hmC}$ achieve functional diversity through differential temporal appearance, chromatin distribution, and binding partner selection in the brain.

\section{MATERIALS AND METHODS ANIMALS}

All mice were used in accordance with National Institute of Health and Indiana University Animal Care and Use (IACUC) guidelines and internationally recognized guidelines. The protocol was approved by the Laboratory Animal Resource Center (LARC) animal ethics committee of Indiana University (protocol ID: 10428). All efforts were made to assure minimal pain and discomfort. C57BL/6 (B6) mice (average 20 grams, 12-14 week old, Harlan, Inc., Indianapolis, IN) were used in this study. Mice were acclimated for at least 1 week before mating. For embryo study, two females were bred with one male for a 2-h period (10:00am12:00noon). The presence of a vaginal plug at the end of the 2-h mating was considered as indicative of conceptus and that hour was designated as embryonic day (E) 0. On E10 and 17 (each $n=8-10$ ), four of the dams were deep anaesthetized with $\mathrm{CO}_{2}$ and embryos were surgically removed from the embryonic sack and fixed in $20 \mathrm{ml}$ of $4 \%$ ice-cold paraformaldehyde (PFA). Dams were then euthanized with cervical dislocation. The rest of the dams gave birth, which was designated postnatal day (P) 0 . On $\mathrm{P} 7, \mathrm{P} 21$, and $\mathrm{P} 45$ ( $n=5-10$ each), mice were anaesthetized with $\mathrm{CO}_{2}$, and then perfused transcardially with $0.9 \%$ saline $(100 \mathrm{ml})$ and $4 \%$ formaldehyde in phosphate buffer $(0.2 \mathrm{M}, \mathrm{pH} 7.4)$. In addition, a group of 3 about 1 year old mice were also used for analysis. The brains were then removed, and post-fixed for at least $24 \mathrm{~h}$ at $4^{\circ} \mathrm{C}$.

\section{IMMUNOHISTOCHEMISTRY}

The embryos and postnatal brain of various ages (E10, E17, P7, $\mathrm{P} 21, \mathrm{P} 45$, and 1 year old) were embedded in gelatin block and fixed with $4 \%$ PFA for $48 \mathrm{~h}$ and sectioned in 40 - $\mu \mathrm{m}$-thick coronal sections on a free-floating vibratome (Leica Microsystems; Buffalo Grove, IL) for immunocytochemical procedures. The sections were then cleared of endogenous peroxidases using $10 \%$ $\mathrm{H}_{2} \mathrm{O}_{2}$ in phosphate buffered saline (PBS) for $10 \mathrm{~min}$, and permeabilized with $1 \%$ TritonX-100 in PBS for $30 \mathrm{~min}$. DNA was denatured with $2 \mathrm{~N} \mathrm{HCL}$ for $30 \mathrm{~min}$, and then neutralized in Tris$\mathrm{HCl}$ ( $\mathrm{PH} \mathrm{7.4)}$ for $10 \mathrm{~min}$. Sections were blocked using a goat kit containing $1.5 \%$ normal goat serum, $0.1 \%$ Triton $\mathrm{X}-100$ in PBS for $1 \mathrm{~h}$, then incubated with primary antibodies. Antibodies used were against DNA methylation marks $5 \mathrm{mC}$ (1:2000, mouse monoclonal; Eurogenetec, Fremont, CA), 5hmC (1:3000, rabbit monoclonal; Active Motif, Carlsbad, CA; The specificity of the crucial anti-5hmC antibody is characterized by pre-absorption of anti-5hmC antibody with 5hmC; See Figure A1); DNA methylation binding proteins $\mathrm{MeCP} 2$ (methyl $\mathrm{CpG}$ binding protein 2, 1:1000, rabbit monoclonal; Cell Signaling, Danvers, MA), MBD1(methyl CpG binding protein 1, 1:500, Millipore, Billerica, MA), MBD3 (methyl CpG binding protein 3, 1:1000, Santa Cruz Biotechnology, Dallas, Texas); DNA methylation enzyme Tet1(ten-eleven translocation 1 , a $5 \mathrm{hmC}$ hydroxylation enzyme; 1:500, rabbit polyclonal; Millipore, Billerica, MA); $5 \mathrm{mC}$ metabolites 5-carboxylcytosine (5caC, 1:1000, Active Motif, Carlsbad, CA) and 5-formylcytosine (5fC, 1:1000, Active Motif, Carlsbad, $\mathrm{CA}$ ); histone marks, trimethyl-H3K4 (H3K4me3, rabbit monoclonal, 1:1000, Millipore, Billerica, MA), trimethyl-H3K9 (H3K9me3, 1:500, Millipore, Billerica, MA), trimethyl-H3K27 (H3K27me3, 1:500, Millipore, Billerica, MA); differentiation markers MAP2 (goat, 1:400, Santa Cruz Biotechnology, Dallas, Texas), anti-nestin (neuroepithelial marker, mouse, 1:500, BD Biosciences, San Jose, CA), and anti-Crabp 1 (cellular retinoic acid binding protein 1 , received from Dr. Wei, University of Missouri); and anti-serine-5 phosphorylated RNA polymerase II (PolII) antibodies (Rabbit, 1:1000; Abcam, Cambridge, MA). Primary antibody was diluted in PBS containing 0.1\% Triton X100 and $1.5 \%$ normal goat-serum. The next day the sections were washed three times in PBS, and then incubated with the corresponding secondary antibodies conjugated with biotin (Jackson ImmunoResearch, West Grove, PA) for single staining or fluorescent dyes (Invitrogen) and for double staining. For single staining, the sections were further incubated in Streptavidin-AP (1:500, Jackson ImmunoResearch, West Grove, PA) for $90 \mathrm{~min}$ and visualized with a brown-colored label, $0.05 \% 3^{\prime}$ - $3^{\prime}$-diaminobenzidine (DAB), and $0.003 \%$ hydrogen peroxide. The sections were then counterstained with methyl green, and dehydrated. For double staining, a second set of primary antibodies were incubated similarly to the first set followed by secondary antibodies with fluorescent dye (Alexa 488, 546, or 633) for $1.5 \mathrm{~h}$ at room temperature. Slices were covered with anti-fade mounting solution with $4^{\prime}, 6^{\prime}$-diamidino-2-phenylindole (DAPI) (Invitrogen). Double-immunocytochemical staining was performed between $5 \mathrm{mC}$ and $5 \mathrm{hmC}$, and the $5 \mathrm{mC}$ with $\mathrm{MBD} 1, \mathrm{MeCP} 2, \mathrm{H} 3 \mathrm{~K} 9 \mathrm{me} 3$, H3K4me2, or serine-5 phosphorylated PolII; and the $5 \mathrm{hmC}$ with MBD3, H3K9me3, H3K4me2, or serine-5 phosphorylated PolII.

\section{IMAGE ACQUISITION}

Confocal fluorescence images were obtained by an Olympus FV1000-MPE Confocal Microscope (Olympus America Inc., Center Valley, PA) mounted on an Olympus IX81 inverted microscope stand with a 60x water-immersed objective lens. Sequential excitation at $488 \mathrm{~nm}$ and $559 \mathrm{~nm}$ was provided by argon and diode lasers, respectively. Emissions were collected by spectral detectors in channels one and two with user-specified min and max wavelengths. A third channel, collecting fluorescence excited at $405 \mathrm{~nm}$ was used for the detection of DAPI. Z-stack images were collected over a thickness of $4.5 \mu \mathrm{m}$ with $0.3 \mu \mathrm{m}$ step intervals. Laser intensities and gain values were adjusted to prevent saturation and to reduce the background noise. The same setting was used over the same pair of staining at different brain locations and ages. After sequential excitation, green, and red fluorescence images of the same cell were saved and analyzed by 
Olympus Fluoview FV10-ASW software (Olympus Corporation 2003-2008).

\section{CO-LOCALIZATION ANALYSIS}

For visualization of co-localization of confocal images, different channels of images were overlaid at the same Z-plane. An overlay of green and red would give rise to yellow hotspots where the two molecules of interest were present in the same pixels. Quantification of co-localization was performed with intensity correlation coefficient-based method using an ImageJ plugin JACoP (http://rsb.info.nih.gov/ij/plugins/track/jacop.html). Methods were adapted from (Bolte and Cordelieres, 2006). Pearson's Coefficients ( $r$ ) were collected for the area of interest in nuclei. The value of $\mathrm{r}$ could range from 1 to -1 , with 1 denoting complete positive correlation, -1 for negative correlation, and 0 for no correlation. The value of $\mathrm{M}$ could vary from 0 to 1 , with 0 corresponding to non-overlapping images and 1 reflecting 100\% co-localization. Each individual cell was outlined by ImageJ selection tool and measured at the same threshold settings. Only the nuclei with $\pm 10 \%$ of the full diameter at section were chosen for the analysis. For each pair of staining, $\sim 20$ cells per staining were measured, respectively, from 3 animals per age, and presented as Mean \pm SEM. Statistical analyses legitimately evaluating colocalization adopted from McDonald and Dunn (2013) were performed with ANOVA for groups or Student's $T$-test for pair comparisons.

\section{FLUORESCENCE LIFETIME IMAGING BASED FORSTER RESONANCE ENERGY TRANSFER (FLIM-FRET) ANALYSIS}

The Immunocytochemistry procedure was done similar to the one described above. In brief, formalin fixed brain tissue section was used. The sections were washed in PBS $3 \times 5 \mathrm{~min}$, then permeabilized using Triton-X 1\% in PBS for $30 \mathrm{~min}$ on a shaker. The first antibody ( $5 \mathrm{mC}$ or $5 \mathrm{hmC}$ ) was labeled with Alexafluor 488 conjugated secondary antibody at 1:500 dilution in nomal goat serum, on a shaker for $90 \mathrm{~min}$, washed for $3(3 \times 5 \mathrm{~min}$; $3 \times 15 \mathrm{~min} ; 4 \times 30 \mathrm{~min}$ ) $\mathrm{h}$. Tissue was then imaged and fluorescence lifetime was measured at the cortex and hypocampus area. The same tissue section was washed for $30 \mathrm{~min}$ on a shaker, and then incubated with a pair of primary antibody (MBD1, MBD3, or MeCP2) for $18 \mathrm{~h}$, and labeled with Alexa fluor 546 conjugated secondary antibody at 1:500 dilution for $90 \mathrm{~min}$, and mounted in the imaging chamber for imaging. For each demethylation $(5 \mathrm{hmc}$, $5 \mathrm{mc}$ )/protein (MBD1, MBD3) interaction 50 cells are used from $\sim 8$ cells/setion of hippocampal or cortical region of 4 P7 brains. Total, 400 cells were used for FLIM-FRET analysis.

FLIM-FRET experiment was performed by measuring the fluorescence lifetime of donor in the absence and the presence of acceptor using Microtime 200 (Picoquant, GmbH, Berlin Germany). Fluorescence lifetime is defined as the time in which fluorescence intensity of a fluorophore is decreased to $1 /$ e of its initial intensity. The source of excitation is a picosecond pulsing diode laser at $467 \mathrm{~nm}$ excitation wavelength for the donor (Alexa fluor 488) and $530 \mathrm{~nm}$ for acceptor (Alexa fluor 546). The laser repetition rate was $40 \mathrm{mHz}$, and the laser power was $\sim 3 \mathrm{~mW}$. The laser was focused on the sample using an apochromatic $60 \mathrm{x}$ water immersion objective with1.2 NA. Off-focus fluorescence was rejected with a $50 \mu \mathrm{m}$ pinhole for efficient collection of the emission. Emitted fluorescence was collected using the same objective and separated from excitation beam using dichroic mirror. Band pass filter $480-520 \mathrm{~nm}$ for Alexa fluor 488, and $570-645 \mathrm{~nm}$ was used to ensure that the collected photons came

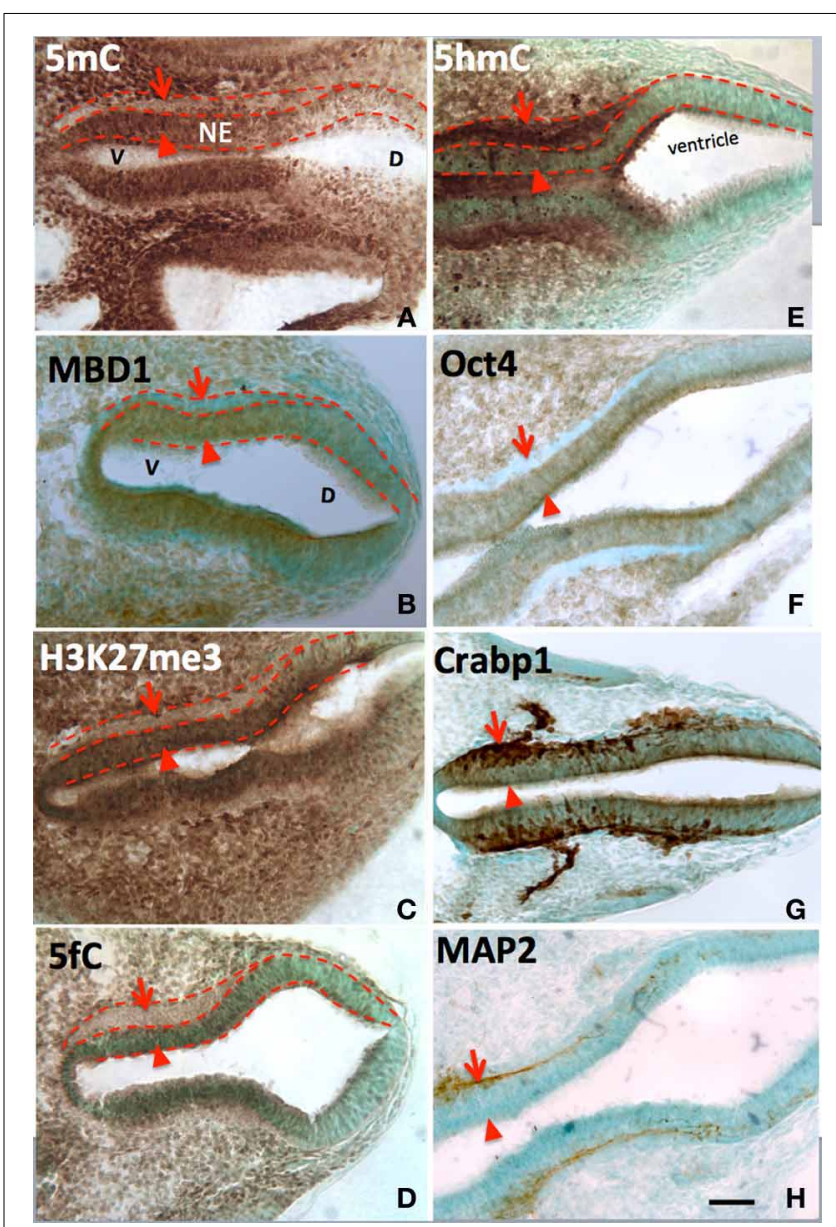

FIGURE 1 | The differential role of $5 \mathrm{mC}$ vs. $5 \mathrm{hmC}$ in the DNA methylation program is inferred by their association with phenotypic marks during the making of neural tube. At early neurulation (E10), a sequential escalation of $5 \mathrm{mC}$ and $5 \mathrm{hmC}$ occurred, where $5 \mathrm{mC}$ appeared first at neuroepithelial (A, NE) layer (arrowheads) to prepare the differentiation, and faded as the NE cells differentiated and migrate away from ventricle ( $\mathbf{A}$, arrows). At this time, the distribution of the DNA methylation binding protein, MBD1, has exactly the same pattern as that of $5 \mathrm{mC}$ (B). Its function is depicted by the suppressive histone mark, H3K27me3, which distributed (C) similar to that of $5 \mathrm{mC}$ and MBD1. The demethylated metabolite $5 \mathrm{fC}$ also matched with $5 \mathrm{mC}$. In contrast, the $5 \mathrm{hmC}$ appeared at differentiating neurons (E, arrowheads) and continued to increase in differentiated neurons (E, arrows). This program also occurred at ventro- (left) dorsal (right) gradation (A-H) where $5 \mathrm{mC}$ (A) preceded $5 \mathrm{hmC}$ (E). The role of $5 \mathrm{mC}$ and $5 \mathrm{hmC}$ on neural tube cell differentiation is further depicted by the differentiation phenotypic markers in a spatially precise manner. The role of the $5 \mathrm{mC}$ is demonstrated by the appearance of the Oct4 in the NE layer (F, arrowhead) and the loss of Oct4 in differentiated neurons ( $\mathbf{F}$, arrow). The role of $5 \mathrm{hmC}$ is noted by the stage-wise neuronal marker Crabp1 (G) and MAP2 (H) distributed in a spatially correlated manner. $V$, ventral; $D$, dorsal. Scale bar: All $=100 \mu \mathrm{m}$. Color scheme: Immunoreactive DAB, brown; counterstaining, methyl green. 
from the donor fluorophore only. Fluorescence emission was collected using two single photon avalanche photodiodes using (SPAD, SPCM-AQR-14, Perkin-Elmer). Each photon was tagged with a time stamp that identifies its arrival time in the detector after the laser pulse, using time correlated single photon counting (TCSPC) in the Time Tagged Time Resolved Single Photon Mode (TTTR) and the FLIM image and the decay curve were obtained. Details of instrumentation can be found in (Varghese et al., 2008; Chen et al., 2012).

Fluorescence lifetime was obtained from the multiexponential reconvolution fitting with the appropriate instrument response function (IRF), following (Lakowicz, 2010; Chen et al., 2011):

$$
I(t)=\sum_{i=1}^{n} \alpha_{1} \exp \left(-\frac{t}{t_{i}}\right)
$$

Time bin was applied to remove the background and threshold was set for 500 photon per pixel. A minimum of 25 different cells from 4 to 5 separate experiments were fitted for efficiency calculations.

FRET efficiency (Vidi et al., 2008) was calculated by:

$$
\text { Efficiency }=1-\frac{\tau a}{\tau b}
$$

where:

$\tau \mathrm{a}=$ Fluorescence lifetime of donor with the absence of acceptor

$\tau \mathrm{a}=$ Fluorescence lifetime of donor with the presence of acceptor
Efficiency above $5 \%$ is considered as significant and vice versa (Ruttinger et al., 2006).

Both the positive and negative controls were also performed by FLIM- FRET to validate our findings. For positive control, we demonstrated that the goat anti-mouse IgG Alexa 488 and donkey anti-goat Alexa 546 IgG (depicting co-localization of the two fluorophores, acceptor and donor,) were within the FRET distance denoting co-localization of the two marks. For negative control, the primary mouse anti-5mC and the secondary antimouse Alexa488 donor (blue channel) does not show any binding proximity to the anti-rabbit Alexa 633 or anti-rabbit Alexa 546 (Acceptor red channel). (See Figure A2).

\section{RESULTS}

\section{ONTOGENY OF DNA METHYLATION OF THE NERVOUS SYSTEM}

At every point of neural differentiation in the neuroepithelial cells throughout the neural tube and brain development, the immunostained $5 \mathrm{mC}$ and $5 \mathrm{hmC}$ appeared or surged in tandemfirst the $5 \mathrm{mC}$ followed by $5 \mathrm{hmC}$ hours to days later. At embryonic day (E) $8-\mathrm{E} 10,5 \mathrm{hmC}$ and $5 \mathrm{mC}$ showed a distinct pattern in the ventricle subpopulation of the neural tube. $5 \mathrm{mC}$ increased in a spatiotemporal gradation, axially from the hindbrain to rostral and caudal neural tube, and at each level from ventral to dorsal aspects. This $5 \mathrm{mC}$ distribution gradient was found to correlate spatiotemporally with the differentiation gradient in the neural tube as reported previously (Zhou et al., 2011). In this report we reveal that, it is the sharp increase of $5 \mathrm{hmC}$, hours to days after the increment of $5 \mathrm{mC}$ that marks the beginning of neuroepithelial cell differentiation. Stages of differentiation were marked
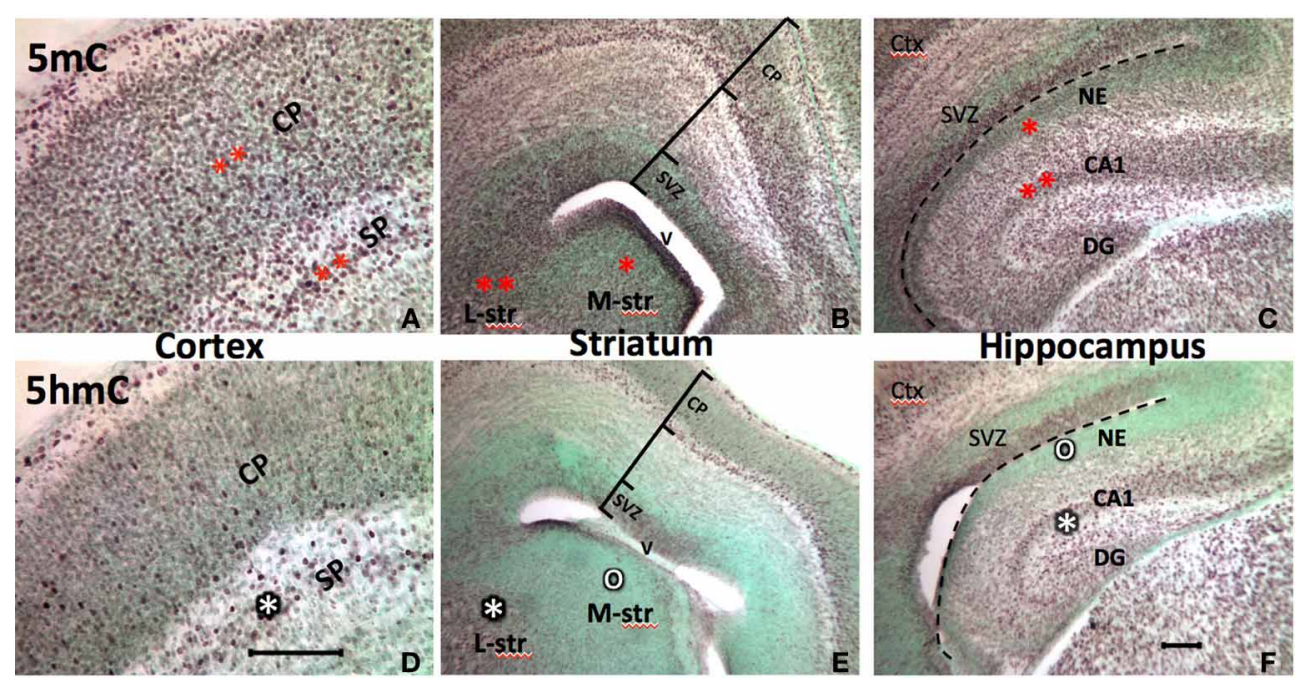

FIGURE 2 | Progression of the 5mC and 5hmC commonly parallels with the neuronal differentiation throughout the developing brain. Also, the sequential escalation of $5 \mathrm{mC}$ precedes $5 \mathrm{hmC}$ at the stage of neural differentiation in the cortex (A vs. D), striatum (B vs. E), and hippocampus (C vs. F) (The degree of methylation is shown by the number of stars, where lack of methylation is denoted by "o"). At the stage of early brain formation at $\mathrm{E} 17$, the $5 \mathrm{mC}$ appeared in the neuroepithelial cells preempting for differentiation (e.g., medial striatum and hippocampal neuroepithelium; B,C, one red star area), and continue in the differentiating neurons in cortex (A), lateral striatum (L-str, B), and CA regions (B, two red stars). The $5 \mathrm{hmC}$ arrives in the cells initiated for differentiation, and the level of $5 \mathrm{hmC}$ parallel with the stage of differentiation, e.g., subplate $>$ cortical plate (D), lateral striatum (L-str) > medial striatum (M-str) (E, white star), CA1>neuroepithelium ( $\mathbf{F}$, white star). Counterstaining, methyl-green (green color). SVZ, subventricular zone; CP, cortical plate; SP, subplate; NE, neuroepithelium; V, ventricle; DG, dentate gyrus. Scale bar: $\mathbf{A}$ and $\mathbf{D}=100 \mu \mathrm{m} ; \mathbf{B}, \mathbf{C}, \mathbf{E}, \mathbf{F}=100 \mu \mathrm{m}$. 
by the sequential appearance of nestin, cRABP, and MAP2 staining (Figure 1). Immunocytochemical staining of $5 \mathrm{hmC}$ coincided with that of Tet1/2 (Figure 1). Throughout all the regions of the differentiating neural tube, the surge of $5 \mathrm{hmC}$ staining can be related to a particular stage of differentiation. Both $5 \mathrm{mC}$ and $5 \mathrm{hmC}$ clearly increased as differentiating neurons migrated toward their targets.

The epigenetic pattern in the developing brain is very similar to that of the neural tube. At early postnatal stage (P7), $5 \mathrm{mC}$ and $5 \mathrm{hmC}$ continue to evolve in the differentiating neurons in the brain where neuroepithelial cells are undergoing differentiation, while less $5 \mathrm{mC}$-immunostaining (im) and no $5 \mathrm{hmC}$-im are noted in the undifferentiated neuroprogenitor cells in the forebrain. For example, an intense $5 \mathrm{mC}$-im and moderate $5 \mathrm{hmC}$-im appeared in differentiated neurons in the lateral striatum, but a low concentration of the $5 \mathrm{mC}$-im and no $5 \mathrm{hmC}$-im appeared in the immature primordial cells in medial striatum at P7 (Figure 2). The timing and partnership of $5 \mathrm{mC}$ and $5 \mathrm{hmC}$ are well demonstrated spatiotemporally in layer development of archicortex (e.g., hippocampus) (Chen et al., 2013) and the neocortex (e.g., frontal cortex) (Figure 2). In more mature brain, e.g., at P45, higher amounts of $5 \mathrm{mC}$ and $5 \mathrm{hmC}$ are distributed in all neurons and glial cells, except the neural progenitor cells in the subventricular zone and subgranular layer of the dentate gyrus where, $5 \mathrm{mC}$-im appeared in low level and $5 \mathrm{hmC}$-im is mostly absent or extremely low, recapitulating the prenatal early neurogenesis. Apparent diverse density of the DNA methylation marks are evident in different regions of the mature brain e.g., striatum vs. cortex, and hippocampus (Figure 2) (As a note, the cellular methylation level in the cerebellum is not exceptionally higher than other regions of the brain as previously indicated in vitro (Kriaucionis and Heintz, 2009). High levels may be due to the biochemical measurement in the high-density granule cells, or a discrepancy between the in vitro and in vivo analysis. Within a region, different intensities of $5 \mathrm{mC}$-im and $5 \mathrm{hmC}$-im were also found in different populations of the neurons during the developmental stages. The intensity of $5 \mathrm{hmC}$ in the brain cells varied to a greater degree than that of $5 \mathrm{mC}$. Both $5 \mathrm{mC}$ and $5 \mathrm{hmC}$ were maintained throughout the young adult stage and in the 1-year-old. A reduction of $5 \mathrm{hmC}$ and $5 \mathrm{mC}$ were found in both neurons (in gray matter) and glial cells (in white matter) in $\sim 1$-year-old brain.

\section{CHROMATIN DYNAMICS}

Initial observation of the surge of $5 \mathrm{mC}$ and $5 \mathrm{hmC}$ by confocal microscopy indicated a diffusely distributed pattern in the nucleus (e.g., in ventral neural tube at E10, or in cortical

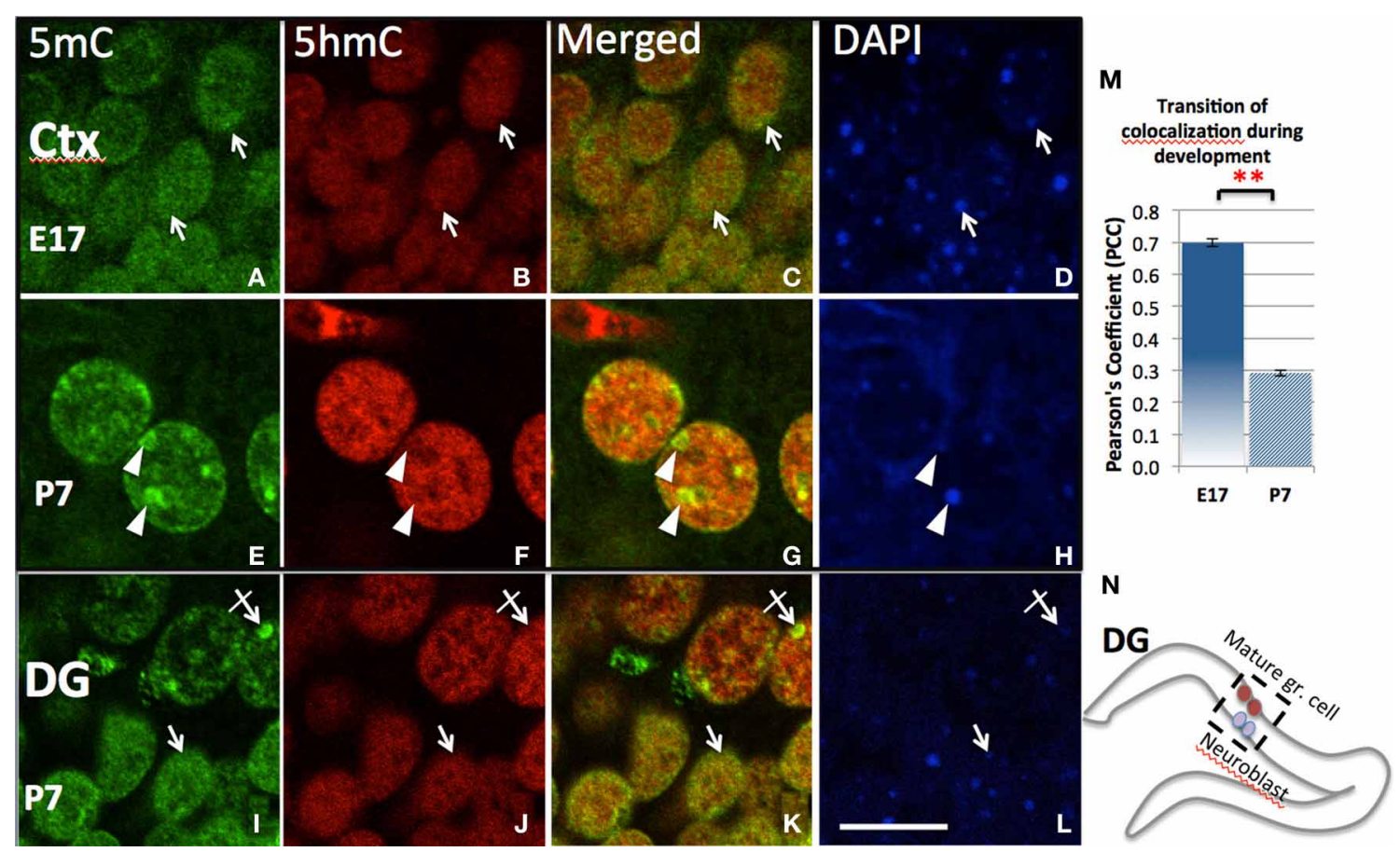

FIGURE 3 | Differential chromatin remodeling of the $5 \mathrm{mC}$ (green) and $5 \mathrm{hmC}$ (red) during neuroprogenitor cell differentiation. In the developing cortex, both $5 \mathrm{mC}$ and $5 \mathrm{hmC}$ were diffusely distributed in undifferentiated cells and many were overlapped at E17 (A-C, D:DAPI. also see quantitation by Pearson's Coefficient analysis in $\mathbf{M}$ ), but polarized into different compartments (E-G; arrows) as the neuron differentiated at P7. The $5 \mathrm{mC}$ (E, arrowheads) became associated with DAPI-dense heterochromatic region ( $\mathbf{H}$, arrowheads), while $5 \mathrm{hmC}$ in contrast with DAPI-sparse eurchromatic region (B,F, arrowhead). The dissociation is indicated by decrease of Pearson's Coefficient between E17 and P 7 shown in chart $\mathrm{m} .{ }^{* *} P<0.005$. Similar remodeling was found in the two differentiating stage of cells within the P7 dentate gyrus (DG; I-L), where undifferentiated or less differentiated (in inner layer, see $\mathbf{N}$ ) and differentiated cells (in outer layer) are layered (see $\mathbf{N}$ ). The $5 \mathrm{mC}$ and $5 \mathrm{hmC}$ were both homogeneously distributed in younger granule cells (I-L, arrows), but $5 \mathrm{mC}$ was translocated into heterchromatic DAPI-dense compartments (I-L; crossed arrow), while $5 \mathrm{hmC}$ was located in euchromatic DAPI-sparse compartment avoiding the heterchromatic DAPI-dense granules ( $\mathbf{J}, \mathbf{K}$, crossed arrow) in the mature granule cells. Scale bar: $(\mathbf{A}-\mathbf{L})=10 \mu \mathrm{m}$. All staining is within nuclei. 
ventricular zone at E17). The degree of co-localization was indicated by Pearson's Coefficient and Manders' Coefficient analysis (see Methods). As the neuroprogenitors progressed to differentiation, $5 \mathrm{mC}$ and $5 \mathrm{hmC}$ co-localization progressively decreased and were finally found in a characteristic complementary mosaic chromatin compartment in the differentiated state, which peaked at early postnatal days (e.g., P7 in the differentiated cortical, hippocampal CA neurons, and lateral striatum). Thus, the $5 \mathrm{mC}$ and $5 \mathrm{hmC}$ within differentiated neuronal nuclei are distinctively distributed in different chromatin compartments, and differentially associated with varying chromatin states. The $5 \mathrm{mC}$ im distributed in $4^{\prime}, 6^{\prime}$-diamidino-2-phenylindole (DAPI)-dense aggregates of heterochromatin regions $(\sim 0.5-1.5 \mu \mathrm{m})$ is completely void of $5 \mathrm{hmC}$-im. The $5 \mathrm{hmC}$-im is solely distributed in fine, DAPI-sparse euchromatic regions $(<0.3 \mu \mathrm{m})$, which also contain small amount of $5 \mathrm{mC}$ (Figure 3). Chromatin remodeling is revealed by the co-localization analysis over a period of time. The mosaic distribution of the $5 \mathrm{hmC}$ and $5 \mathrm{mC}$ is also demonstrated by their association with DNA methylation binding proteins and histone codes associated with gene transcription states shown below.

\section{DIFFERENTIAL BINDING PARTNERS}

$5 \mathrm{mC}$ and $5 \mathrm{hmC}$ are differentially associated with methyl CpG binding domain (MBD) protein in neurons throughout the brain (e.g., cortices, hippocampus, and cerebellum). By confocal microscopy, double staining revealed a distinct partnership between MBDs and the $5 \mathrm{mC}$ and $5 \mathrm{hmC}$. MeCP2 appeared in the neural tube where neurons formed as early as the mouse embryo day 10 (E10) following the appearance of $5 \mathrm{mC}$ by approximately a day. The $5 \mathrm{mC}$ co-localized with the $\mathrm{MeCP} 2$ with remarkably high-fidelity (Figure 4). The co-localization was found in the large DAPI-dense aggregates as well as in the fine DAPI-sparse chromatin particles in the differentiated neurons. In contrast, the $5 \mathrm{hmC}$, which is devoid of DAPI-dense aggregates, does not overlap with aggregated (heterochromatic) MeCP2 in either compartment of the chromatin (Figure 4). Co-localization of $5 \mathrm{mC}$ and its binding partners $\mathrm{MeCP} 2$ and MBD1 evolved as the brain
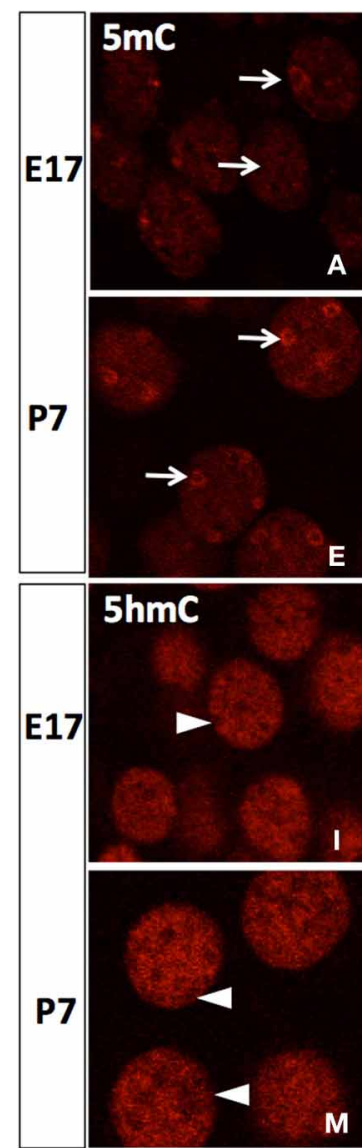
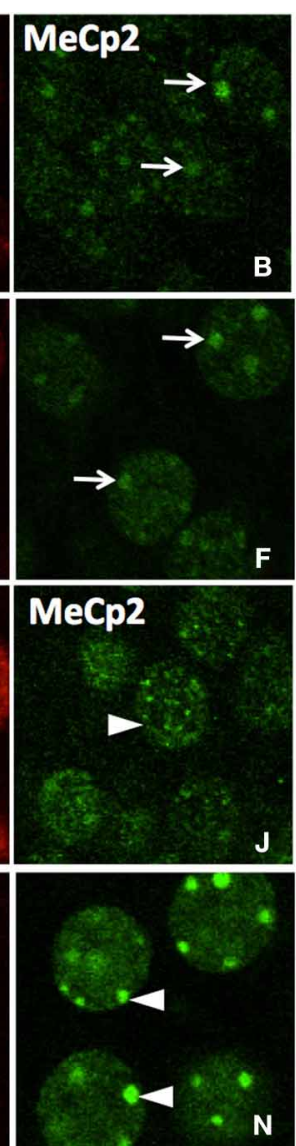
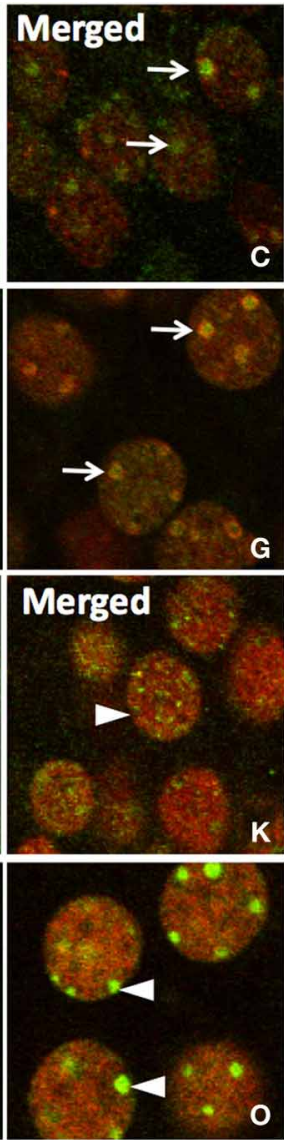
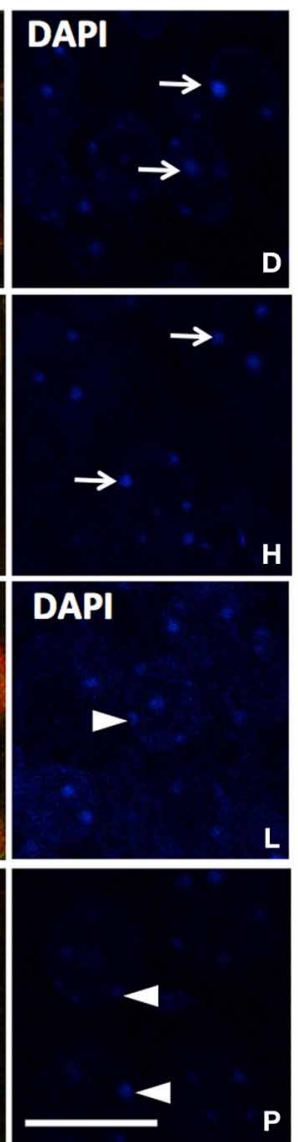

Q

Colocalization of

$\mathrm{MeCp2}$ with $5 \mathrm{mC}$ in developing cortex

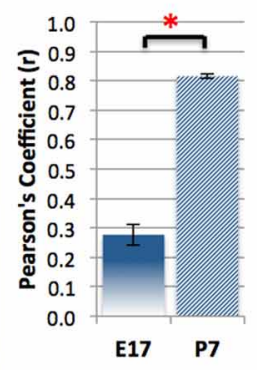

\section{$\mathbf{R}$}

Colocalization of $\mathrm{MeCp} 2$ with $5 \mathrm{hmC}$ in developing cortex

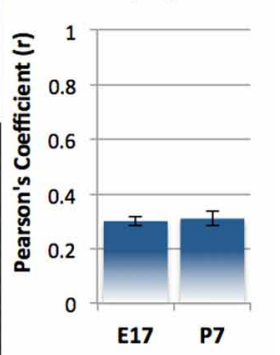

FIGURE 4 | The transitional association of MeCP2 from $5 \mathrm{mC}$ to $5 \mathrm{hmC}$ during neuronal maturation. The association of $\mathrm{MeCP} 2$ with $5 \mathrm{mC}$ is consolidated as neurons mature shown in the cortex. Nuclear distribution of methyl-binding protein 2 (MeCP2) is homogeneous and mildly associated with $5 \mathrm{mC}(\mathbf{A}-\mathbf{D})$ at E17 but greatly increased at P7 in cortex (E-H). Pearson's Coefficient ( $r$ ) for co-localization was shown in the chart (Q). In contrast, the homogeneously (euchromatic) distributed MeCP2 colocalized with $5 \mathrm{hmC}$ at
E17 (I-L, arrowhead), but the aggregated (heterochromatic) MeCP2 dissociated with $5 \mathrm{hmC}$ (colocalized instead with $5 \mathrm{mC}$ as shown in $\mathbf{E}-\mathbf{H}$ ) in more mature neurons at P7 (M-P, arrowhead). Pearson's coefficient for co-localization was shown in chart (R). Scale bar: All $=10 \mu \mathrm{m}$. It is shown that MeCP2 (D,N; arrowheads) are mostly distributed at DAPI-dense region with heterchromatin (D,H; arrowheads) where $5 \mathrm{hmC}$ is usually absent (I,M; arrowheads). Scale bar: all $=10 \mu \mathrm{m} .{ }^{*} p<0.05$. 
developed, with co-localization of $5 \mathrm{mC}$ and $\mathrm{MeCP} 2$ occurring prior to that of $5 \mathrm{mC}$ and $\mathrm{MBD} 1$. The $5 \mathrm{mC}$ and $\mathrm{MBD} 1$ which were partially colocalized and homogeneously distributed in DAPIsparse regions in early development (e.g., at E17), became highly colocalized and translocated to mostly heterochromatic aggregates in the cortex (Figure 5) and other brain regions of similar maturation stage. In contrast, the $5 \mathrm{hmC}$-im is highly co-localized with MBD3 throughout specific brain regions, e.g., in cortex
(Figure 5). The $5 \mathrm{mC}$ and $\mathrm{MBD} 3$ localization in contrast has been low (not shown).

To better enumerate and validate the binding partners, DNA methylation-MBD interaction in real-time, Fluorescence Lifetime Imaging based Forster Resonance Energy Transfer (FLIM-FRET) approach was utilized for precise evaluation of the interactions. We demonstrated that there was low interaction between $5 \mathrm{hmC}$ and MBD1 in either hippocampus (FRET efficiency 2.98\%) or
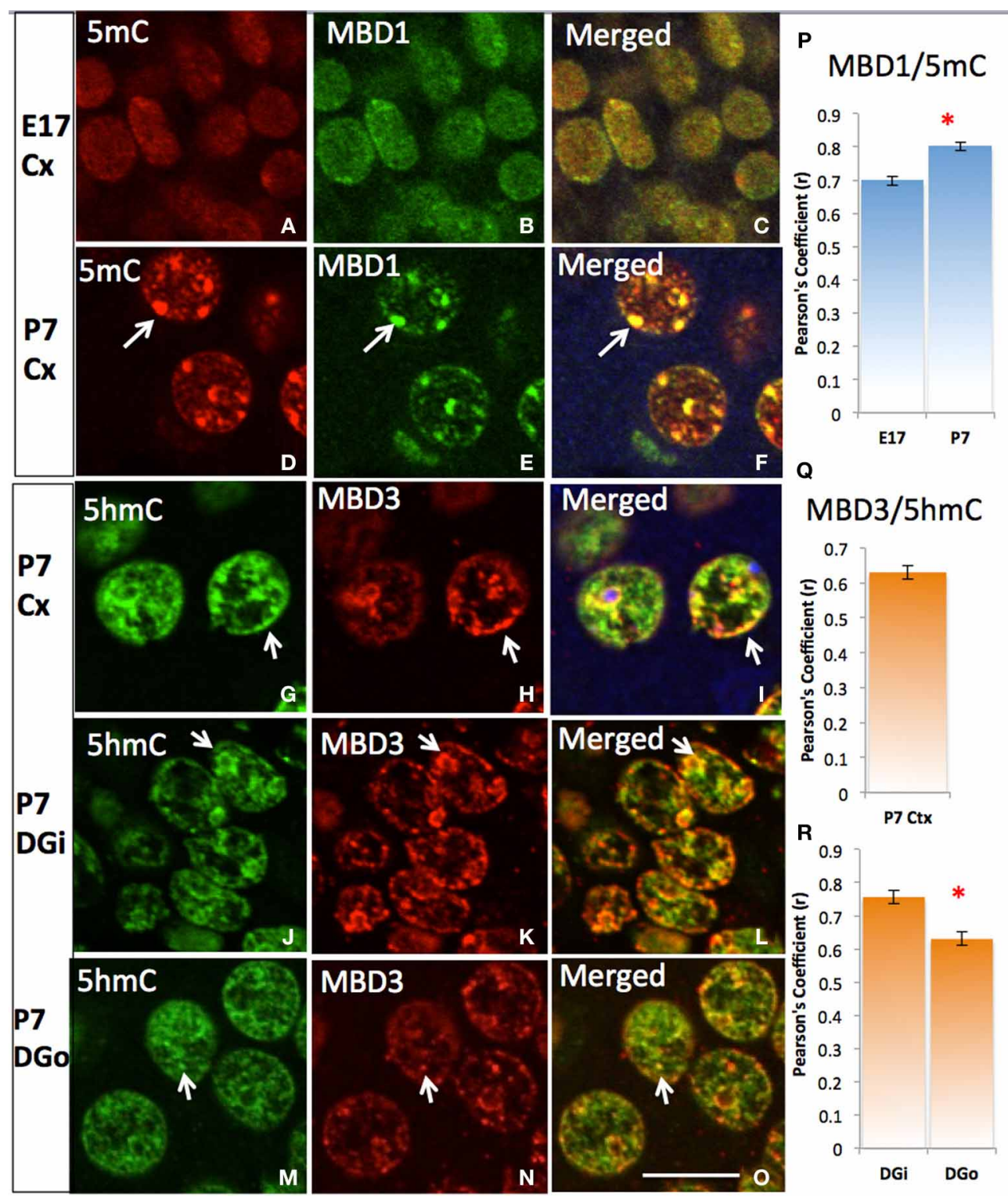

FIGURE 5 | Differential DNA methylation binding protein partners and their co-translocation during chromatin remodeling over the stage of neuronal maturation. Two color-fluorescent confocal microscopy shows that the $5 \mathrm{mC}$ (red) predominantly co-localized (A, red) with MBD1 (B, green) initially in the homogeneous small punctate form at nuclei of young E17 neurons at layer IV of cortex (CX) (C), and increasing their co-localization (P) and strikingly co-located in the heterochromatin aggregates when became more differentiated by P7 (D-F, arrows). The colocalization of $5 \mathrm{hmC}$ (G, green) with MBD3 $(\mathbf{H}$, red) were seen at E17 (not shown) and P7 (G-I, Pearson's Coefficient is shown in $\mathbf{Q}$ ) in the cortex and in the dentate gyrus (R). The $5 \mathrm{hmC}$ co-locates with MBD3 to homogeneous euchromatic region (DAPI sparse, now show) from young neurons at inner layer of dentate gyrus $(\mathrm{DGi}, \mathbf{J}-\mathbf{L})$ to older outer layer dentate gyrus (DGo, M-O). Scale bar: All $=10 \mathrm{um}$. The Pearson's Coefficient analyses of colocalization are shown on $(\mathbf{P}-\mathbf{R}) .{ }^{*} p<0.05$. 
cortex (FRET efficiency 1.11\%) (Figure 6A). In contrast, strong interaction between $5 \mathrm{mC}$ and MBD1 (FRET efficiency 8.579.65\%) (Figure 6B) and between 5hmC and MBD3 (FRET efficiency 7.68-8.40\%) in both hippocampus and cortex (Figure 6C) were noted.

\section{DIFFERENTIAL ASSOCIATION WITH SPECIFIC CODE OF HISTONE AND TRANSCRIPTION SITE}

The double-staining of DNA methylation with histone codes indicated that $5 \mathrm{mC}$ favorably co-localizes with $\mathrm{H} 3 \mathrm{~K} 9 \mathrm{me} 3$ and with $\mathrm{H} 3 \mathrm{~K} 27 \mathrm{me} 3$, which are mostly located in the DAPI-dense aggregates (Figure 7). On the contrary, $5 \mathrm{hmC}$ does not co-localize with $\mathrm{H} 3 \mathrm{~K} 9 \mathrm{me} 3$ or H3K27me3. Instead, it co-localizes with H3K4me2 in the DAPI-sparse regions while a lack of co-localization between $5 \mathrm{mC}$ with $\mathrm{H} 3 \mathrm{~K} 4 \mathrm{me} 2$ (Figure 7) is noted. The divergent $5 \mathrm{mC}$ and $5 \mathrm{hmC}$ co-localization with histone codes is independent of the development stage (e.g., E17, P7, P28) and is observed throughout the brain (the cortices, hippocampus, brainstem, and cerebellum).

The differential role of $5 \mathrm{mC}$ and $5 \mathrm{hmC}$ is summarized by its association with the PolII transcription enzyme for transcription initiation (Serine-5 phosphorylated PolII) (Cho et al., 2001; Cheng and Sharp, 2003). A strong co-localization of 5hmC with PolII was shown during neuronal differentiation throughout the emerging (E17) stage and slightly decreased in more matured (P7) neurons as demonstrated in the cortex (Figure 8). The co-localization between $5 \mathrm{mC}$ and PolII was transient and dissociated as neuronal differentiation progressed at P7 as indicated by the Pearson's coefficient (Figure 8I).

\section{STABLE EXISTENCE OF DEMETHYLATION INTERMEDIATES 5hmC, 5fC, AND 5caC}

Although a slight reduction in the subpopulation of cells was observed, the $5 \mathrm{mC}$ and $5 \mathrm{hmC}$ remain throughout, in $\sim 1$ year-old brain (e.g., thalamus, basal ganglia) compared to that of young adult. $5 \mathrm{hmC}$ 's appearance in the prenatal stage shows that it is a prominent feature in neural cells, and persists throughout the life span in the brain as observed in our early time points of E8 and E10, to P7, P21, P45, and 1 year-old (Figure 9). Apparently, 5hmC is not a temporary intermediate as noted from samples obtained from different ages of the brain. We next observed that the demethylation forms, $5 \mathrm{fC}$ and $5 \mathrm{caC}$, which exist in smaller concentration compared to that of $5 \mathrm{mC}$ and $5 \mathrm{hmC}$, appear during

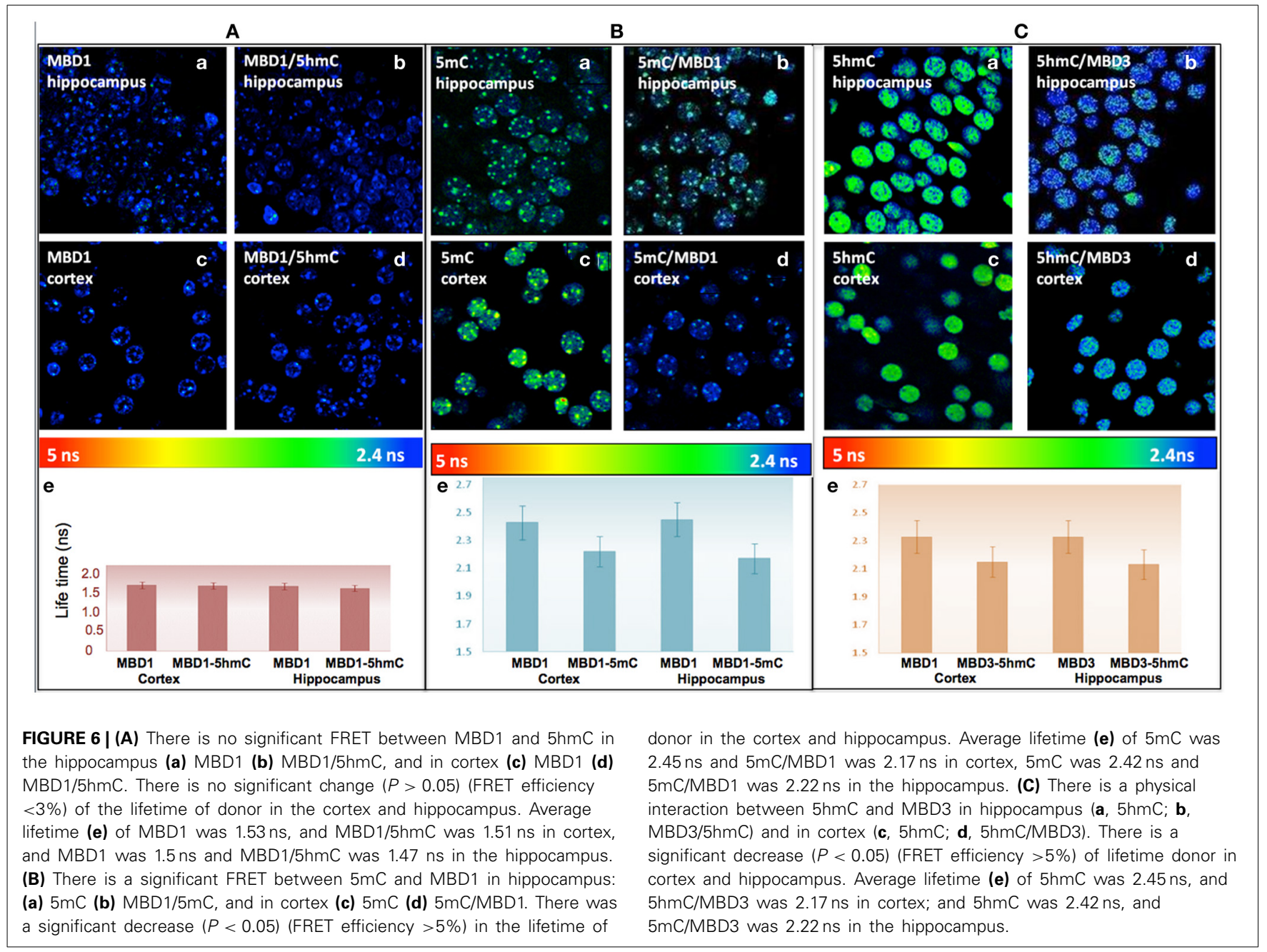



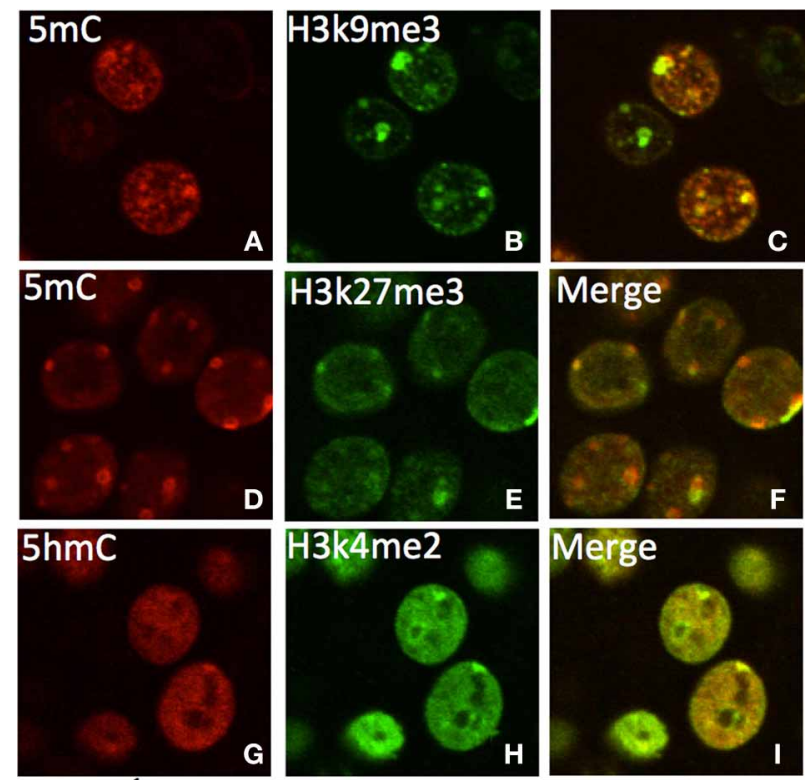

J

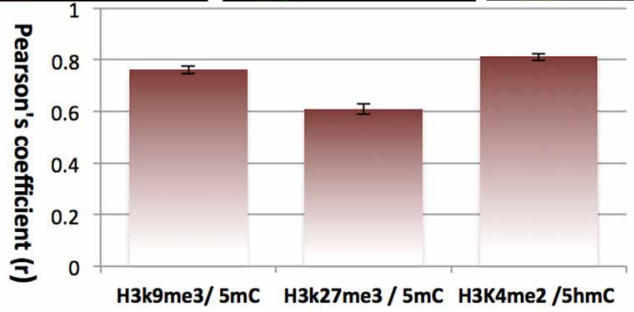

FIGURE 7 | Differential colocalization of $5 \mathrm{mC}$ and $5 \mathrm{hmC}$ with histone marks in nuclei of differentiated neurons in P7 cortex indicated by two color-fluorescence confocal microscopy. The $5 \mathrm{mC}(\mathbf{A}, \mathbf{D}$, red) is closely colocalized with suppressive histone marks $\mathrm{H} 3 \mathrm{~K} 9 \mathrm{me} 3$ (B, green) (merged in C), and H3K27me3 (E, green) (merged in F). In contrast, the $5 \mathrm{hmC}$ (G, red) is highly co-localized with the activating histone mark, H3K4Me2 (H, green) as demonstrated in the merged image (I). Pearson's coefficient is shown in chart $\mathbf{J}$. Data presented as Mean \pm SEM.

early development (E10, E17) and exist in the nervous system from the prenatal stage throughout adulthood (e.g., P21, P45) (Figure 9). Thus, it is evident that the demethylation intermediate and the demethylated cytosine variants are lasting marks on DNA.

\section{DISCUSSION}

\section{5mC AND 5hmC TRANSITION DURING DEVELOPMENT}

$5 \mathrm{mC}$ and $5 \mathrm{hmC}$ co-distribute as early as in the zygote stage, where most of the DNA methylation is inherited. Global demethylation eliminated most of the DNA methylation in the early zygotic development during implantation (Kafri et al., 1993; Morgan et al., 2005; Inoue et al., 2011; Iqbal et al., 2011; Salvaing et al., 2012). We found that during neurulation there is a sharp escalation of DNA methylation. The escalation is not random but rather progressed in a pattern closely associated with the state of differentiation of the neuroprogenitor cells. Both $5 \mathrm{mC}$ and $5 \mathrm{hmC}$ progressed in the newly differentiated neuroepithelial cells as observed from the spatiotemporal patterns in the neural tube and developing brain. However, there are two major differences between the two DNA methylation marks. First, the temporal surge of $5 \mathrm{mC}$ and $5 \mathrm{hmC}$ is punctual (at very specific stage of neural differentiation) and step-wise (always escalation of $5 \mathrm{mC}$ first and followed with $5 \mathrm{hmC}$ ) throughout developing pre- and postnatal brain (where neural differentiation occurs). The latter is not surprising since it is in agreement with the sharp rise of the TET enzyme, which oxidizes $5 \mathrm{mC}$ into $5 \mathrm{hmC}$ (Figure 1). However, very interestingly, it is the timing of the surge of $5 \mathrm{hmC}$, but not $5 \mathrm{mC}$, that marks the initiation of neural progenitor cell differentiation. Our experiments show that the escalation of $5 \mathrm{mC}$ coincides with the shutdown of proliferation just prior to neural stem cell differentiation; and that the surge of $5 \mathrm{hmC}$, which is involved in transcription, coincides with neural differentiation. The transition from $5 \mathrm{mC}$ to $5 \mathrm{hmC}$ upon initiation of progenitor cell differentiation and determination of cell fate is ubiquitous throughout the brain regions observed and depending on the stage of neural stem cells instead of overall age of the brain. This pattern is carried into the adult neural stem cells, where $5 \mathrm{mC}$ and $5 \mathrm{hmC}$ sequentially escalated in newly stem post-mitotic mature neurons, while little-to-low $5 \mathrm{hmC}$ is observed in undifferentiated adult progenitor cells near the ventricle and in the hippocampal sub-granular layer (Chen et al., 2013).

\section{5hmC IS NOT A TRANSIENT INTERMEDIATE}

Is $5 \mathrm{hmC}$ merely an intermediate state of demethylation, serving no biological function? Recently, instead of being transient and unstable, $5 \mathrm{hmC}$ was detected as a relatively stable epigenetic marker in ES or zygotic cells (Inoue and Zhang, 2011; Iqbal et al., 2011). The following evidence lead us to believe that $5 \mathrm{hmC}$ is not a transient intermediate of demethylation, although it is not without turnover, as we previously indicated in the ontogeny of DNA methylation (Zhou et al., 2011; Zhou, 2012). Our observations that $5 \mathrm{mC}$ and $5 \mathrm{hmC}$ co-distribute throughout neurulation and brain development, and that $5 \mathrm{hmC}$ exists and persists throughout the life span of neurons strongly argues against the notion that $5 \mathrm{hmC}$ is merely an intermediate product. Further, we found the demethylation products $5 \mathrm{fC}$ and $5 \mathrm{caC}$, which are also recently being considered for potential functionality (Burgess, 2012; Kellinger et al., 2012), are stably expressed in the developing neurons and throughout the mature brain. Taken together, this evidence support our claim that that $5 \mathrm{hmC}$ is a long-standing and dynamic component.

\section{5hmC IS A LEAGUE OF ITS OWN}

Is $5 \mathrm{hmC}$ a genuinely new breed of DNA methylation? Apparently, $5 \mathrm{hmC}$ and $5 \mathrm{mC}$ can be discriminated via their binding partners. Our evidence thus far suggests that at least they are read by distinctly different binding proteins $-5 \mathrm{mC}$ preferentially binds to MeCP2 and MBD1, while 5hmC preferentially binds to MBD3. Recent reports indicate a mix view on the association of $5 \mathrm{hmC}$ vs. $5 \mathrm{mC}$ to MBD3 (Yildirim et al., 2011; Hashimoto et al., 2012; Spruijt et al., 2013). All these studies were conducted in vitro and mostly in ES cells. Given the dynamic nature of DNA methylation, the evolution of the respective binding partner is also likely dynamic, potentially resulting in differences between in vitro and in vivo interactions. Our observations, obtained throughout brain development demonstrated that there is a dynamic transition of 

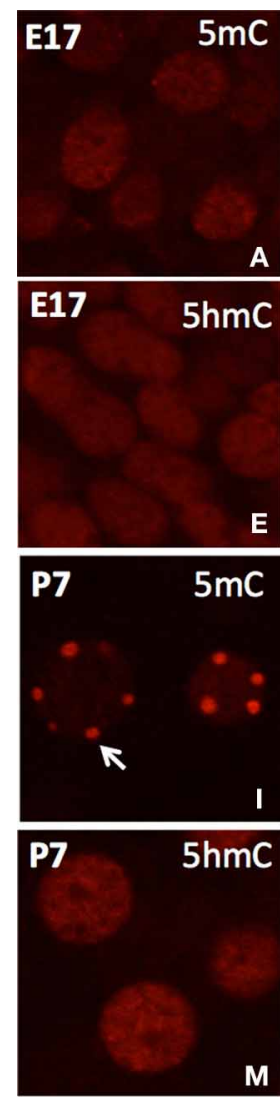
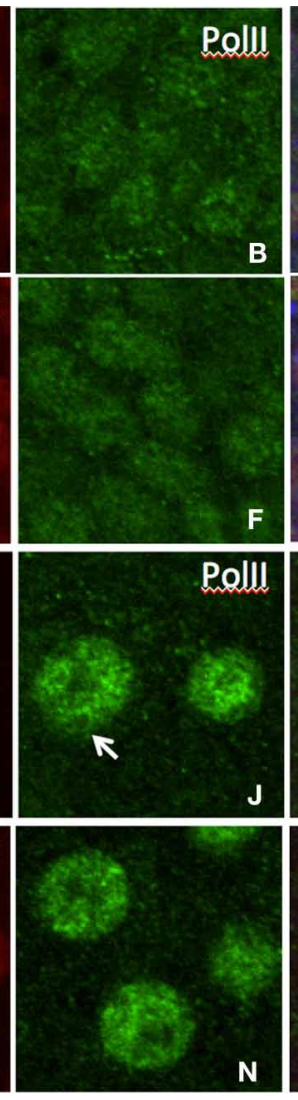
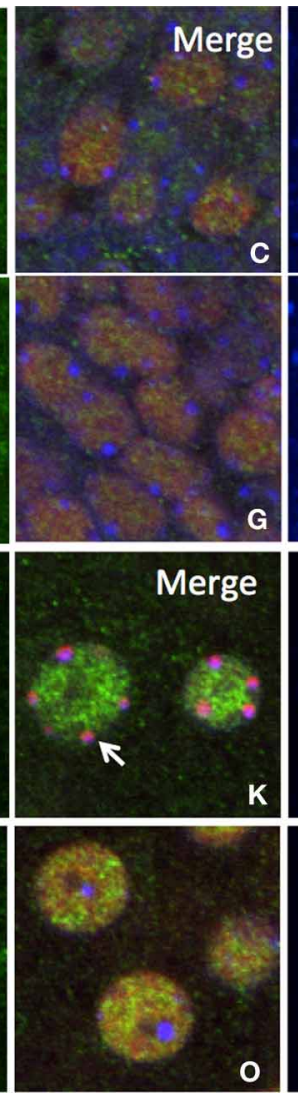
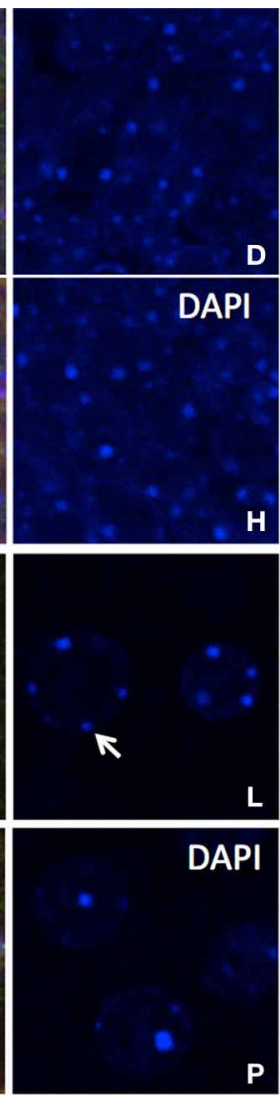

Q

POL II Ser-5 phosphorylation / $5 \mathrm{hmC}$ and $5 \mathrm{mC}$

$=$ PoLII $/ 5 \mathrm{mC}=$ PoLII $/ 5 \mathrm{hmC}$

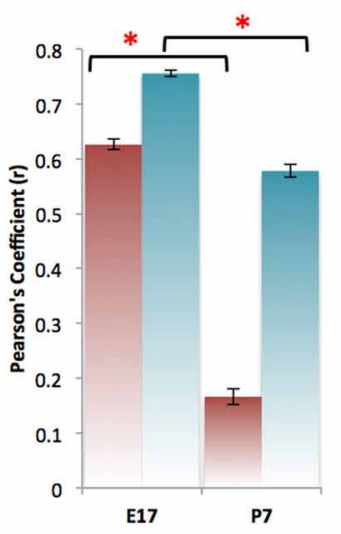

FIGURE 8 | Differential co-localization of Polll (transcription elongation enzyme) with $5 \mathrm{hmC}$ over $5 \mathrm{mC}$ in the cortex as demonstrated in confocal microscopy. At stage of early differentiating (E17), both $5 \mathrm{mC}$ (A-D) and to a greater extend $5 \mathrm{hmC}(\mathbf{E}-\mathbf{H})$ are associated the Polll. As neurons mature (P7), Po/ll dissociates with $5 \mathrm{mC}$ (I-L, $\mathbf{Q}$, arrows), while specifically associates with $5 \mathrm{hmC}(\mathbf{M}-\mathbf{Q})$. The $5 \mathrm{hmC}$ (red) and Po/ll (green) sites are all in the euchromatic regions exclusive from DAPI stained heterochromatic region (blue, Arrow). Pearson's analysis of co-localization of DNA methylation marks and $\mathrm{Po} / \mathrm{II}$ indicates that the initial co-localization between $5 \mathrm{mC}$ and Po/ll were notedly was diminished at the later stage (0). This observation summarizes the differential role of $5 \mathrm{mC}$ and $5 \mathrm{hmC}$ on transcription. ${ }^{*} p<0.05$. this differential binding coincident with neuronal differentiation through the neural developmental stage (Figure 5). The bona fide differential binding activities of $5 \mathrm{mC}$ with $\mathrm{MBD} 1$ and $5 \mathrm{hmC}$ with MBD3 partners are demonstrated here by the FLIM-FRET analysis for the first time (Figure 6). This observation affirms the previous finding which points to the fact that in differential genomic distribution that $5 \mathrm{mC}$ is preferentially localized in the promoter regions of the gene, while $5 \mathrm{hmC}$ and $\mathrm{MBD} 3$ is preferentially distributed in the downstream transcription starting sites (TSS) in the gene body regions (Stroud et al., 2011; Wu et al., 2011; Yildirim et al., 2011).

Functionally, the genes associated with $5 \mathrm{hmC}$ in the gene bodies are actively transcribed in the mouse embryonic stem cells and mouse cerebellum (Guo et al., 2011; Pastor et al., 2011; Wu et al., 2011). The functional diversity of the two forms of DNA methylation is further suggested in the current study by their cellular affiliation first with correspondent histone codes$5 \mathrm{mC}$ with the suppressive $\mathrm{H} 3 \mathrm{~K} 9 \mathrm{me} 3$ and with $\mathrm{H} 3 \mathrm{~K} 27 \mathrm{me} 3$, mostly in the heterochromatin regions; and $5 \mathrm{hmC}$ with $\mathrm{H} 3 \mathrm{~K} 4 \mathrm{me} 2$ in the euchromatin regions (Figure 7). This methylation transition and histone code affiliation is also demonstrated at the genomic level. $5 \mathrm{hmC}$ is enriched in the TSS in the gene body close to regions of $\mathrm{H} 3 \mathrm{~K} 4 \mathrm{me} 2$, but not near $\mathrm{H} 3 \mathrm{~K} 9 \mathrm{me} 3$ regions. Further, $5 \mathrm{hmCs}$ are also enriched in regions associated with activating the histone codes H3K4mel and H3K27ac (Stroud et al., 2011). In genes, $5 \mathrm{hmC}$ transitions from silent to activated, and was found to affiliate with the activating $\mathrm{H} 3 \mathrm{~K} 4 \mathrm{me} 3$ and suppressive H3K27me3 in ES cells (Pastor et al., 2011; Williams et al., 2011). Perhaps the strongest evidence that we have observed is the co-localization of $5 \mathrm{hmC}$ with PolII in the euchromatin regions throughout neuronal differentiation, and the transient and complete dissociation of $5 \mathrm{mC}$ and PolII throughout chromatin in nucleus (Figure 8). Together, these observations indicate that the conversion of $5 \mathrm{mC}$ to $5 \mathrm{hmC}$ is a dynamic process that may serve as a means for transcriptional transition to regulate ES cells in previous studies (see introduction) and those of the developing nervous system (Zhou et al., 2011; Zhou, 2012; Chen et al., 2013). On the other hand, after 5hmC has settled in mature neurons, significantly long-term high levels of $5 \mathrm{hmC}$, as well as $5 \mathrm{fC}$ and $5 \mathrm{caC}$, were observed through adulthood. This indicates that $5 \mathrm{hmC}$ is not a transient intermediate toward demethylation, rather it is highly associated with 


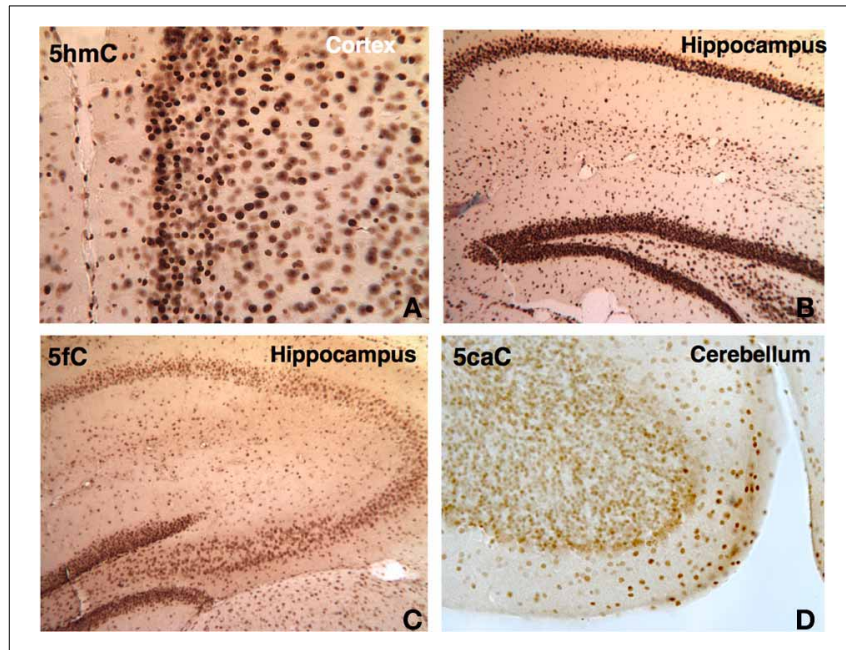

FIGURE 9 | DNA methylation intermediates were observed to be persistent throughout the life in the brain. A few examples are shown here. The $5 \mathrm{hmC}$ persists in the cortex (A) and hippocampus (B) in 1 year-old brain. The demethylated cytosine marks also prevailed. The $5 \mathrm{fC}$ is shown in the hippocampus at P21 (C), and 5caC (D) in cerebellum at P45.

euchromatin and likely maintains the activity of genes for cell specificity.

\section{CHROMATIN REMODELING}

The significance of the escalation of $5 \mathrm{mC}$ and $5 \mathrm{hmC}$ during the course of neuroepithelial cell differentiation has to do with chromatin remodeling and DNA packaging. We found that the selective DNA methylation and histone marks are progressively distributed differentially to correspond with the DAPI-dense vs. -sparse chromatin compartments. In the developing brain, at perinatal stage (E15-P7), $5 \mathrm{mC}$ relocates from DAPI sparse to the DAPI-dense heterochromatin, while $5 \mathrm{hmC}$ affiliates with DAPIsparse euchromatin. The $5 \mathrm{mC}$ and $5 \mathrm{hmC}$ associated chromatin remodeling peaking at $\mathrm{P} 7$ coincides with synaptogenesis. Another event of DNA methylation reconfiguration-where CpG methylation (mCG) is switching to non-CpG methylation $(\mathrm{mCH})$ also coincides with synaptogenesis (Lister et al., 2013). These two events highlight the dynamics of DNA methylation during brain development.

The above distinct differential affiliations provide a major clue suggesting a departure of $5 \mathrm{hmC}$ from $5 \mathrm{mC}$ and a transition toward transcriptional activation. It infers that the transition from $5 \mathrm{mC}$ to $5 \mathrm{hmC}$ is pertinent to chromatin remodeling and to DNA packaging in the different compartments for the silenced vs. activated gene cohorts for timely functional or developmental progression during neural fate determination or tissue specification. The differential association of $5 \mathrm{mC}$ with suppressive histone codes, and $5 \mathrm{hmC}$ with activation histone code, further support chromatin remodeling to organize the transcription transition. An epigenomic-gene expression analysis in the hippocampus and cerebellum (Szulwach et al., 2011) supports this view. Meehan et al. (Nestor et al., 2012) recently further demonstrated that $5 \mathrm{hmC}$ is associated with transcribed genes.

\section{CONCLUSIONS}

We demonstrated that $5 \mathrm{mC}$ dramatically increased in the neuroprogenitor cells during priming for differentiation, and preferentially binds to MBD1 (as indicated by FLIM-FRET), and colocalizes with MeCP2, histone $\mathrm{H} 3 \mathrm{~K} 9 \mathrm{me} 3$ and $\mathrm{H} 3 \mathrm{~K} 27 \mathrm{me}$, and is finally packed into heterochromatin during and after neural differentiation. $5 \mathrm{mC}$ is likely to organize a more selective transcription during differentiation. In contrast, $5 \mathrm{hmC}$ surged at the initiation of differentiation of neuroepithelial cells, preferentially bound to MBD3, colocalized with the euchromatin histone $\mathrm{H} 3 \mathrm{~K} 4 \mathrm{me} 2$, and gradually translocated to the euchromatin, demonstrating a transition to transcription that is needed for differentiation. Thus, $5 \mathrm{mC}$ and $5 \mathrm{hmC}$, which divided into different chromatin and differentially associated with distinct functional partners through development and remained in adulthood, likely represent functionally unique DNA methylations in the epigenetic landscape. This added complexity in the epigenome may increase the efficiency with which the complex journey of development is accomplished, and may improve the responsiveness of the system to the environmental inputs (Zhou, 2012; Chen et al., 2013; Resendiz et al., 2013).

\section{ACKNOWLEDGMENTS}

The studies were supported by the M. W. Keck Foundation to Joseph Irudayaraj and Feng C. Zhou, by National Institute of Health [AA016698, P50 AA07611 to Feng C. Zhou]; and by Indiana University Collaborative Research Grant to Feng C. Zhou. Yuanyuan Chen and Nur P. Damayanti are graduate students. We like to thank Ms. Alison Batka for editing the manuscipt.

\section{REFERENCES}

Bhutani, N., Burns, D. M., and Blau, H. M. (2011). DNA demethylation dynamics. Cell 146, 866-872. doi: 10.1016/j.cell.2011.08.042

Bolte, S., and Cordelieres, F. P. (2006). A guided tour into subcellular colocalization analysis in light microscopy. J. Microsc. 224, 213-232. doi: 10.1111/j.13652818.2006.01706.x

Burgess, D. J. (2012). Technology: genome-wide mapping of 5-formylcytosine. Nat. Rev. Genet. 13, 675. doi: 10.1038/nrg3344

Chen, J., Miller, A., Kirchmaier, A. L., and Irudayaraj, J. M. K. (2012). Singlemolecule tools elucidate H2A.Z nucleosome composition. J. Cell Sci. 125, 2954-2964. doi: 10.1242/jcs. 101592

Chen, J., Nag, S., Vidi, P.-A., and Irudayaraj, J. (2011). Single molecule in vivo analysis of toll-like receptor 9 and CpG DNA interaction. PLoS ONE 6:e17991. doi: 10.1371/journal.pone.0017991

Chen, Y., Ozturk, N. C., and Zhou, F. C. (2013). DNA methylation program in developing hippocampus and its alteration by alcohol. PLoS ONE 8:e60503. doi: 10.1371/journal.pone.0060503

Cheng, C., and Sharp, P. A. (2003). RNA polymerase II accumulation in the promoter-proximal region of the dihydrofolate reductase and gammaactin genes. Mol. Cell. Biol. 23, 1961-1967. doi: 10.1128/MCB.23.6.1961-19 67.2003

Cho, E. J., Kobor, M. S., Kim, M., Greenblatt, J., and Buratowski, S. (2001). Opposing effects of Ctk1 kinase and Fcpl phosphatase at Ser 2 of the RNA polymerase II C-terminal domain. Genes Dev. 15, 3319-3329. doi: 10.1101/gad.935901

Globisch, D., Munzel, M., Muller, M., Michalakis, S., Wagner, M., Koch, S., et al. (2010). Tissue distribution of 5-hydroxymethylcytosine and search for active demethylation intermediates. PLoS ONE 5:e15367. doi: 10.1371/journal.pone.0015367

Guo, J. U., Su, Y., Zhong, C., Ming, G. L., and Song, H. (2011). Hydroxylation of 5methylcytosine by TET1 promotes active DNA demethylation in the adult brain. Cell 145, 423-434. doi: 10.1016/j.cell.2011.03.022 
Hashimoto, H., Liu, Y., Upadhyay, A. K., Chang, Y., Howerton, S. B., Vertino, P. M., et al. (2012). Recognition and potential mechanisms for replication and erasure of cytosine hydroxymethylation. Nucleic Acids Res. 40, 4841-4849. doi: 10.1093/nar/gks155

Inoue, A., Shen, L., Dai, Q., He, C., and Zhang, Y. (2011). Generation and replication-dependent dilution of $5 \mathrm{fC}$ and $5 \mathrm{caC}$ during mouse preimplantation development. Cell Res. 21, 1670-1676. doi: 10.1038/cr.2011.189

Inoue, A., and Zhang, Y. (2011). Replication-dependent loss of 5hydroxymethylcytosine in mouse preimplantation embryos. Science 334, 194. doi: $10.1126 /$ science. 1212483

Iqbal, K., Jin, S. G., Pfeifer, G. P., and Szabo, P. E. (2011). Reprogramming of the paternal genome upon fertilization involves genome-wide oxidation of 5-methylcytosine. Proc. Natl. Acad. Sci. U.S.A. 108, 3642-3647. doi: 10.1073/pnas. 1014033108

Ito, S., D’Alessio, A. C., Taranova, O. V., Hong, K., Sowers, L. C., and Zhang, Y. (2010). Role of Tet proteins in $5 \mathrm{mC}$ to $5 \mathrm{hmC}$ conversion, ES-cell selfrenewal and inner cell mass specification. Nature 466, 1129-1133. doi: 10.1038/ nature 09303

Ito, S., Shen, L., Dai, Q., Wu, S. C., Collins, L. B., Swenberg, J. A., et al. (2011). Tet proteins can convert 5-Methylcytosine to 5-Formylcytosine and 5-Carboxylcytosine. Science 333, 1300-1303. doi: 10.1126/science.1210597

Kafri, T., Gao, X., and Razin, A. (1993). Mechanistic aspects of genome-wide demethylation in the preimplantation mouse embryo. Proc. Natl. Acad. Sci. U.S.A. 90, 10558-10562. doi: 10.1073/pnas.90.22.10558

Kellinger, M. W., Song, C.-X., Chong, J., Lu, X.-Y., He, C., and Wang, D. (2012). 5formylcytosine and 5-carboxylcytosine reduce the rate and substrate specificity of RNA polymerase II transcription. Nat. Struct. Mol. Biol. 19, 831-833. doi: 10.1038/nsmb.2346

Kriaucionis, S., and Heintz, N. (2009). The nuclear DNA base 5hydroxymethylcytosine is present in Purkinje neurons and the brain. Science 324, 929-930. doi: 10.1126/science.1169786

Lakowicz, J. R. (2010). Principles of Fluorescence Spectroscopy. New York, NY: Kluwer Academic/Plenum Publishers.

Lister, R., Mukamel, E. A., Nery, J. R., Urich, M., Puddifoot, C. A., Johnson, N. D., et al. (2013). Global epigenomic reconfiguration during mammalian brain development. Science 341, 1237905. doi: 10.1126/science. 1237905

McDonald, J. H., and Dunn, K. W. (2013). Statistical tests for measures of colocalization in biological microscopy. J. Microsc. 252, 295-302. doi: 10.1111/jmi.12093

Morgan, H. D., Santos, F., Green, K., Dean, W., and Reik, W. (2005). Epigenetic reprogramming in mammals. Hum. Mol. Genet. 14 Spec No 1, R47-R58. doi: 10.1093/hmg/ddil14

Nestor, C. E., Ottaviano, R., Reddington, J., Sproul, D., Reinhardt, D., Dunican, D., et al. (2012). Tissue type is a major modifier of the 5-hydroxymethylcytosine content of human genes. Genome Res. 22, 467-477. doi: 10.1101/gr.126417.111

Pastor, W. A., Pape, U. J., Huang, Y., Henderson, H. R., Lister, R., Ko, M., et al. (2011). Genome-wide mapping of 5-hydroxymethylcytosine in embryonic stem cells. Nature 473, 394-397. doi: 10.1038/nature10102

Resendiz, M., Chen, Y., Ozturk, N. C., and Zhou, F. C. (2013). Epigenetic medicine and fetal alcohol spectrum disorders. Epigenomics 5, 73-86. doi: 10.2217/epi.12.80

Ruttinger, S., Macdonald, R., Kramer, B., Koberling, F., Roos, M., and Hildt, E. (2006). Accurate single-pair Forster resonant energy transfer through combination of pulsed interleaved excitation, time correlated single-photon counting, and fluorescence correlation spectroscopy. J. Biomed. Optic. 11, 024012. doi: $10.1117 / 1.2187425$

Salvaing, J., Aguirre-Lavin, T., Boulesteix, C., Lehmann, G., Debey, P., and Beaujean, N. (2012). 5-Methylcytosine and 5-hydroxymethylcytosine spatiotemporal profiles in the mouse zygote. PLoS ONE 7:e38156. doi: 10.1371/journal.pone.0038156

Spruijt, C. G., Gnerlich, F., Smits, A. H., Pfaffeneder, T., Jansen, P. W. T. C., Bauer, C., et al. (2013). Dynamic readers for 5-(hydroxy)methylcytosine and its oxidized derivatives. Cell 152, 1146-1159. doi: 10.1016/j.cell.2013.02.004
Stroud, H., Feng, S., Morey Kinney, S., Pradhan, S., and Jacobsen, S. E. (2011). 5 -Hydroxymethylcytosine is associated with enhancers and gene bodies in human embryonic stem cells. Genome Biol. 12, R54. doi: 10.1186/gb-2011-126-r54

Szulwach, K. E., Li, X., Li, Y., Song, C. X., Wu, H., Dai, Q., et al. (2011). 5-hmCmediated epigenetic dynamics during postnatal neurodevelopment and aging. Nat. Neurosci. 14, 1607-1616. doi: 10.1038/nn.2959

Tahiliani, M., Koh, K. P., Shen, Y., Pastor, W. A., Bandukwala, H., Brudno, Y., et al. (2009). Conversion of 5-methylcytosine to 5-hydroxymethylcytosine in mammalian DNA by MLL partner TET1. Science 324, 930-935. doi: 10.1126/science. 1170116

Varghese, L., Sinha, R., and Irudayaraj, J. (2008). Single molecule kinetic investigations of protein association and dissociation using fluorescence cross-correlation spectroscopy. Anal. Chim. Acta 625, 103-109. doi: 10.1016/j.aca.2008.07.021

Vidi, P.-A., Chen, J., Irudayaraj, J. M. K., and Watts, V. J. (2008). Adenosine A(2A) receptors assemble into higher-order oligomers at the plasma membrane. FEBS Lett. 582, 3985-3990. doi: 10.1016/j.febslet.2008.09.062

Williams, K., Christensen, J., Pedersen, M. T., Johansen, J. V., Cloos, P. A., Rappsilber, J., et al. (2011). TET1 and hydroxymethylcytosine in transcription and DNA methylation fidelity. Nature 473, 343-348. doi: 10.1038/nature10066

Wolffe, A. P., Jones, P. L., and Wade, P. A. (1999). DNA demethylation. Proc. Natl. Acad. Sci. U.S.A. 96, 5894-5896. doi: 10.1073/pnas.96.11.5894

Wossidlo, M., Nakamura, T., Lepikhov, K., Marques, C. J., Zakhartchenko, V., Boiani, M., et al. (2011). 5-Hydroxymethylcytosine in the mammalian zygote is linked with epigenetic reprogramming. Nat. Commun. 2, 241. doi: $10.1038 /$ ncomms 1240

Wu, H., D’Alessio, A. C., Ito, S., Wang, Z., Cui, K., Zhao, K., et al. (2011). Genomewide analysis of 5-hydroxymethylcytosine distribution reveals its dual function in transcriptional regulation in mouse embryonic stem cells. Genes Dev. 25, 679-684. doi: 10.1101/gad.2036011

Wu, S. C., and Zhang, Y. (2010). Active DNA demethylation: many roads lead to Rome. Nat. Rev. Mol. Cell Biol. 11, 607-620. doi: 10.1038/nrm2950

Xu, Y., Wu, F., Tan, L., Kong, L., Xiong, L., Deng, J., et al. (2011). Genome-wide regulation of $5 \mathrm{hmC}, 5 \mathrm{mC}$, and gene expression by Tetl hydroxylase in mouse embryonic stem cells. Mol. Cell. 42, 451-464. doi: 10.1016/j.molcel.2011.04.005

Yildirim, O., Li, R., Hung, J. H., Chen, P. B., Dong, X., Ee, L. S., et al. (2011). Mbd3/NURD complex regulates expression of 5-hydroxymethylcytosine marked genes in embryonic stem cells. Cell 147, 1498-1510. doi: 10.1016/j.cell.2011.11.054

Zhou, F. C. (2012). DNA methylation program during development. Front. Biol. 7:485-494. doi: 10.1007/s11515-012-9246-1

Zhou, F. C., Chen, Y., and Love, A. (2011). Cellular DNA methylation program during neurulation and its alteration by alcohol exposure. Birth Defects Res. A Clin. Mol. Teratol. 91, 703-715. doi: 10.1002/bdra.20820

Conflict of Interest Statement: The authors declare that the research was conducted in the absence of any commercial or financial relationships that could be construed as a potential conflict of interest.

Received: 03 December 2013; accepted: 12 February 2014; published online: 10 March 2014.

Citation: Chen Y, Damayanti NP, Irudayaraj J, Dunn Kand Zhou FC (2014) Diversity of two forms of DNA methylation in the brain. Front. Genet. 5:46. doi: 10.3389/fgene. 2014.00046

This article was submitted to Epigenomics and Epigenetics, a section of the journal Frontiers in Genetics.

Copyright (c) 2014 Chen, Damayanti, Irudayaraj, Dunn and Zhou. This is an openaccess article distributed under the terms of the Creative Commons Attribution License (CC BY). The use, distribution or reproduction in other forums is permitted, provided the original author(s) or licensor are credited and that the original publication in this journal is cited, in accordance with accepted academic practice. No use, distribution or reproduction is permitted which does not comply with these terms. 


\section{APPENDIX}

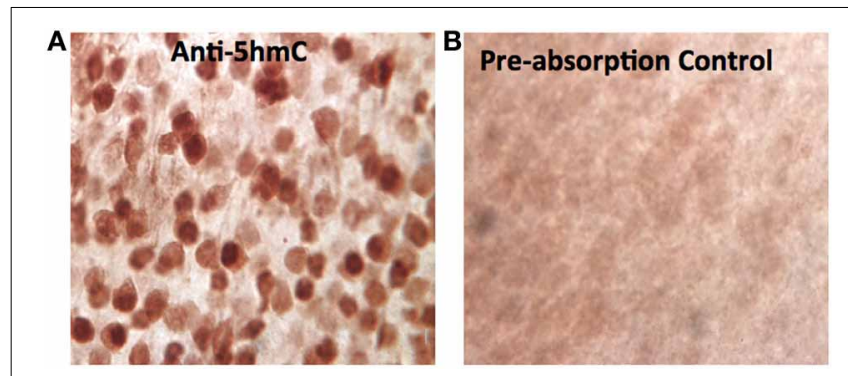

FIGURE A1 | The specificity of the anti-5hmC antibody. The specificity of the crucial anti-5hmC antibody against $5 \mathrm{hmC}$ was characterized by

pre-absorption of anti-5hmC antibody (1:1000, rabbit polyclonal IgG, Active Motif) with $5 \mathrm{hmC}$ synthesized DNA (Methylated DNA Standard Kit, \#55008, Active Motif, $50 \mathrm{ng} / \mu \mathrm{l}$, at a working dilution of 1:20 molar ratio) overnight at $4^{\circ} \mathrm{C}$. Before absorption, the anti-5hmC immunostaining in the cortex shows distinct $5 \mathrm{hmC}$ staining pattern (A) as described in the result, while the staining pattern was abolished or drastically reduced after 5hmC-preabsorption (B).
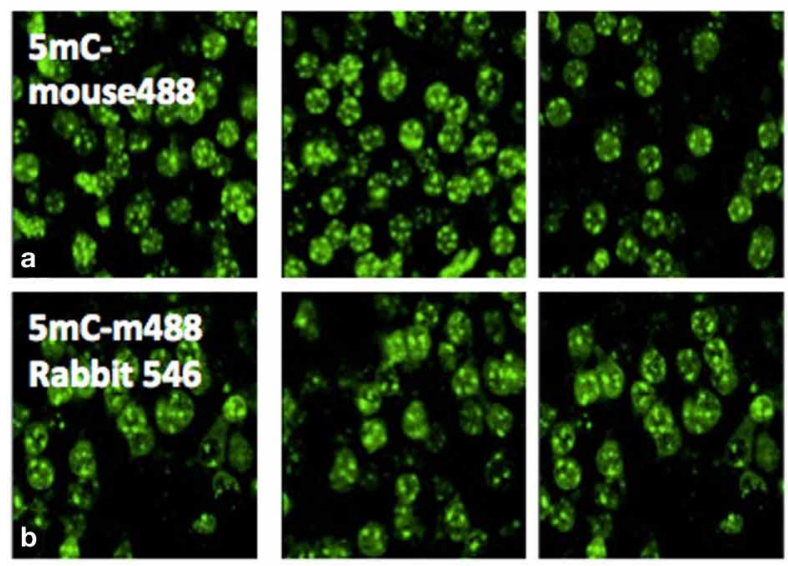

\section{A Negative Control 0 ns}

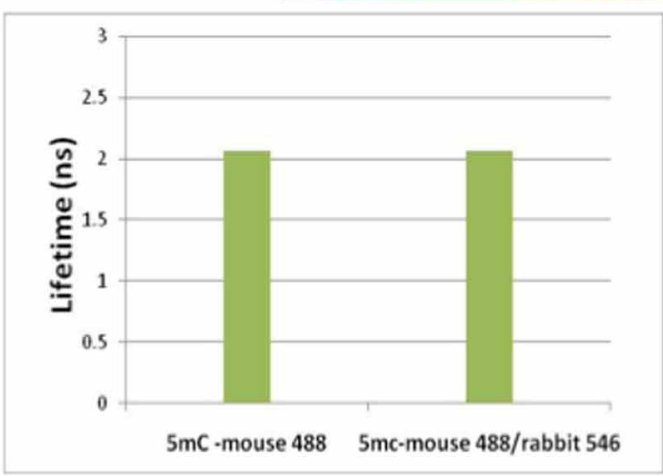

FIGURE A2 | Positive and negative control study by FLIM-FRET. (A) Negative control: There is no interaction between mouse IgG Alexa488 and anti Rabbit IgG Alexa546. (a) Average lifetime anti-5mC mouse IgG Alexa488 was $2.128 \mathrm{~ns}$. (b) Average lifetime of anti-5mC mouse IgG Alexa488 and mouse anti rabbit-ant lgG Alexa546 was $2.120 \mathrm{~ns}$. There is no significant change (FRET efficiency $>0.05$ and at $P>0.05)$ between mean lifetime of donor and acceptor in
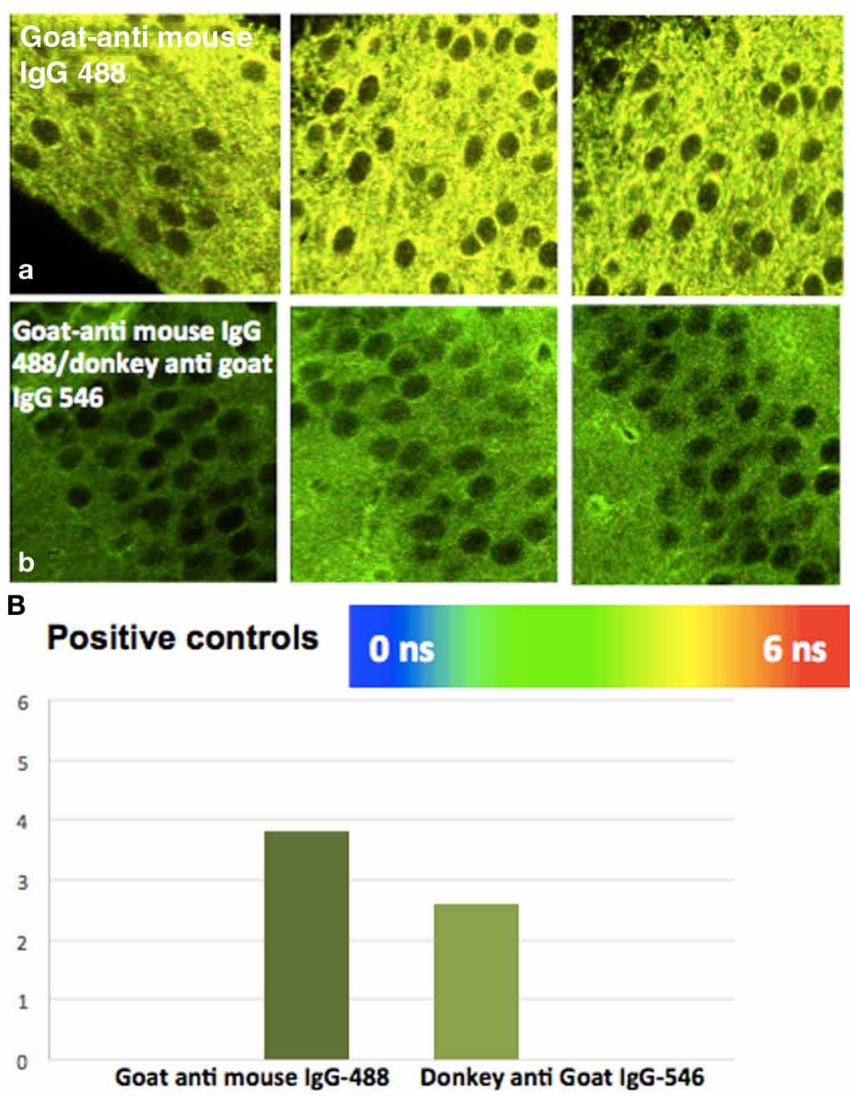

hippocampus. (B) Positive controls: There is interaction between goat/anti-mouse IgG Alexa488 and anti-goat lgG. (a) Average lifetime of goat-anti mouse IgG Alexa488 was $3.8 \mathrm{~ns}$, while (b) the average lifetime of goat anti-mouse IgG Alexa488 and anti-goat IgG Alexa546 was $2.6 \mathrm{~ns}$. There is significant change (FRET efficiency $>0.05$ and at $P<0.05)$ between mean lifetime of lifetime donor and acceptor in the hippocampus. 